DERRIDA'S TYPOLOGY: ON THE STATUS OF A DECONSTRUCTIVE LOGIC

\author{
by
}

\title{
Henry Goury-Laffont
}

B.A., Philosophy and Liberal Arts (Concordia University, 2014)

\author{
A thesis \\ presented to Ryerson University \\ in partial fulfillment of \\ Master of Arts (M.A.) \\ in the Program of \\ Philosophy \\ Toronto, Ontario, Canada, 2016 \\ (C) Henry Goury-Laffont 2016
}




\section{AUTHOR'S DECLARATION FOR ELECTRONIC SUBMISSION OF A THESIS}

I hereby declare that I am the sole author of this thesis. This is a true copy of the thesis, including any required final revisions, as accepted by my examiners.

I authorize Ryerson University to lend this thesis to other institutions or individuals for the purpose of scholarly research.

I further authorize Ryerson University to reproduce this thesis by photocopying or by other means, in total or in part, at the request of other institutions or individuals for the purpose of scholarly research.

I understand that my thesis may be made electronically available to the public. 


\section{Table of Contents}

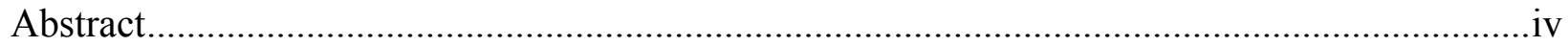

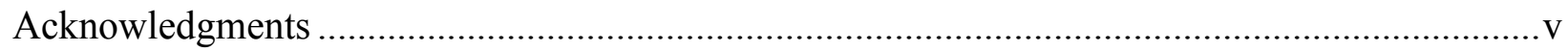

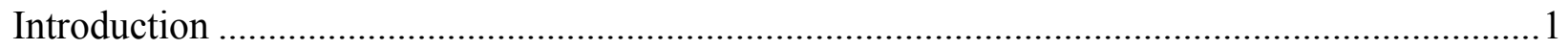

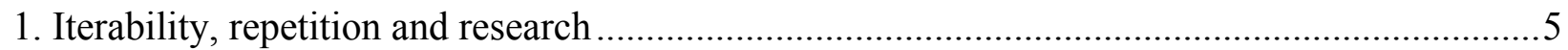

1.1 Iterability in Signature Event Context ................................................................. 7

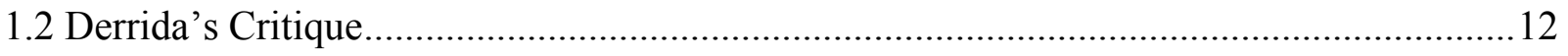

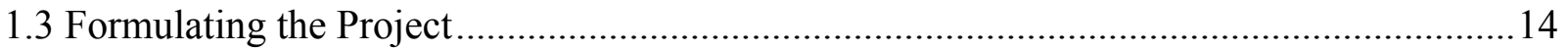

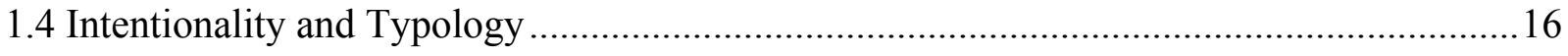

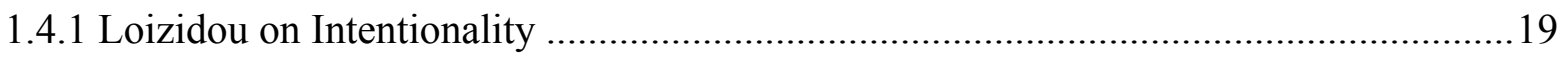

2. Quasi-Transcendental Forms of Iteration ..........................................................................25

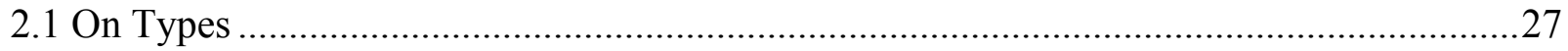

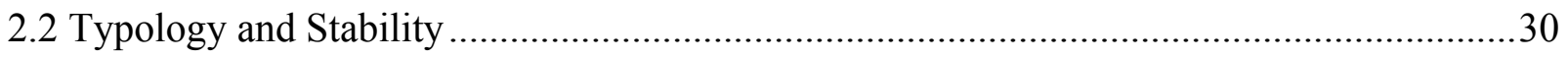

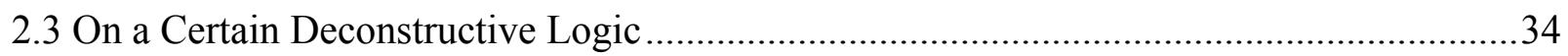

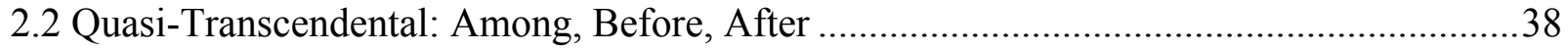

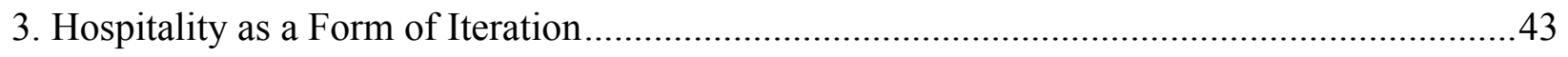

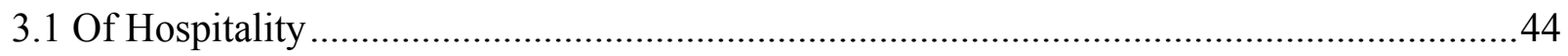

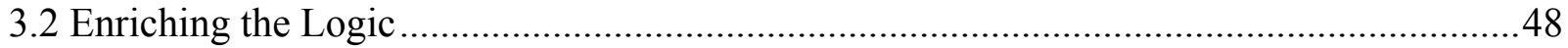

3.3 On the Transposition of a Deconstructive Logic .....................................................51

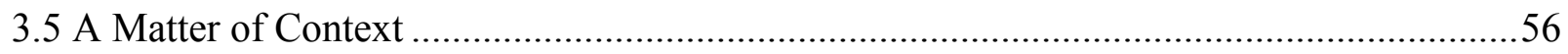

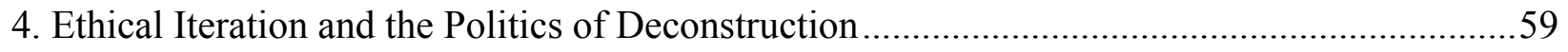

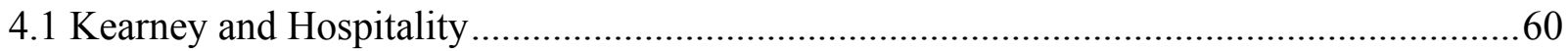

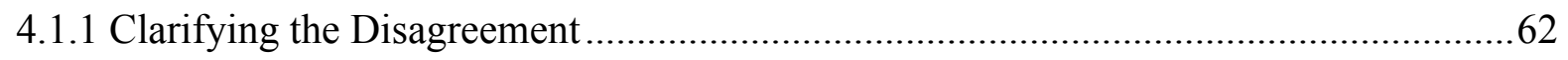

4.2 Khôra: Alterity as a Political Resource ........................................................................65

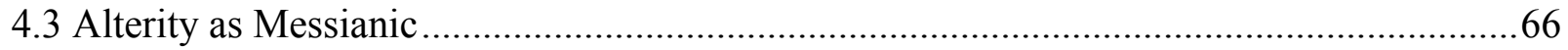

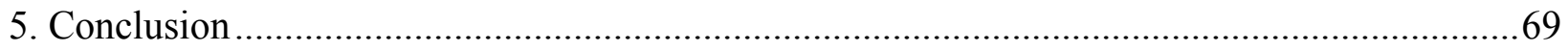


Abstract

\section{Derrida's Typology: On the Status of a Deconstructive Logic Henry Goury-Laffont Master of Arts (2016), Department of Philosophy, Ryerson University}

This thesis begins with a simple question: what is the status of a theory of construction? Is such a theory itself constructed? What does this tell us about the post-structuralist or deconstructive reappropriation of research and theory? To address these questions, this thesis makes two moves. The first consists in identifying a general argumentative structure or logic of construction at work across several of Jacques Derrida's published works. The second move consists in thinking through how this logic reconfigures itself by affecting the status of theories or explanatory models. We will argue that a 'deconstructive logic', if there is such a thing, cannot be final, fixed and atemporal. Departing from previous interpretations of Derrida's work, we will make the case that this is not simply a negative limitation: rather, it marks a commitment to a localized mode of philosophy, or thinking on the terms of a particular context. 


\section{Acknowledgments}

I must first acknowledge an impossible debt to Dr. John Caruana for confronting me with (even more) impossible texts that have kept me busy these past years, and I suspect, will remain with me for a long time.

I would also like to thank Dr. Paula Schwebel for her extensive help and advice this past year. I am grateful to the other members of my examining committee, Dr. David Ciavatta and Dr. Glenn Parsons, for their insightful feedback and questions.

Finally, I would like to thank Dr. Ferda Keskin at Istanbul Bilgi University and Dr. Martin Hägglund at Yale University for allowing me to do research abroad this past year, and for offering me new perspectives on old problems.

Many others have made this possible; but for now, they will remain tucked away in another archive. 
$\underline{\text { Introduction }}$

"Everything in the delineation of différance is strategic and adventurous." (Derrida 1972, 7)

Derrida is often thought of as a soixante-huitard, a thinker characterized by a certain spirit materialized in the events of May 1968 in France. His various philosophical endeavors could, on this reading, be aligned with the kind of departure from the strong conception of national identity and culture inherent in Charles de Gaulle's tenure at the head of the French state. While this narrative deserves consideration in relation to Derrida's work, it should not overshadow the specificity of his thought. Unlike many of his contemporaries at the École Normale Supérieure, Derrida will not stick to a particular political or party line during the rest of his life: rather, his political involvement, like his writing, is piecemeal, disseminated, occurring in different, specific contexts. Today, as French society is marked by the idealization or rebranding of a national "identity" - most notably through the continued rise of the prosovereignty Front National, the publication of Eric Zemmour's best-selling Le Suicide Francais, the reinforcement of various European borders or the implicitly nationalist responses to terrorist attacks (“Je Suis Charlie”) - Derrida's critique, more than ever, should be closely considered.

Yet Derrida's move, as we will attempt to show, is first and foremost a complication rather than a rejection of questions of identity and of the "proper" ('propre' in French, as 'clean', as 'proper meaning' - sens propre - or as 'one's own': son propre). One of the most apparent manifestations of this commitment appears within his writing: dozens of texts published over Derrida's lifetime engage with a wide range of topics ranging from linguistics to, in his later days, ethics and politics. The complication - rather than rejection - of continuity, identity and fixity appears most clearly in the relation between these different texts. A reader of Derrida, after engaging with even a fraction of his corpus, will quickly come to observe the recurrence of certain philosophical moves or patterns within his work. On the other hand, the systematization of deconstruction, a project that has kept scholars busy since Derrida's appearance in the American academy, is no simple affair. Several concerns arise in relation to this project: what are we to do with the specificities of Derrida's specific interventions? Does a systematization of his thought not undermine the importance of writing alluded to in Derrida's early work? 
Several answers to these questions have been put forth in deconstructive scholarship. Some, such as Martin Hägglund (2008), have focused on the remarkable consistency of a certain 'logic' within Derrida's thought, which we will later come to consider. Others, including John D. Caputo (2006), have remarked upon the fragmentary nature of Derrida's project, and the way in which the contexts of his later interventions mark a stark departure from his early work. The latter reading is often understood in relation to an 'ethical turn' in Derrida's thought, and more generally, in contemporary French philosophy. Both of these moves, however, risk falling into a number of problems identified in Derrida's interventions. A reduction of deconstruction to a master 'logic' undermines the importance of context and writing so crucial to the deconstructive project; on the other hand, the identification of a "new" deconstruction appearing in the late works disregards the unmistakable continuity of Derrida's thought.

This thesis will attempt a third answer. By turning to Derrida's early work on language, we will seek to account for the relation between a general deconstructive logic and its specific context through the framework of a typology. This concept, taken from the early Signature Event Context, will serve as our guiding element to provide a more rigid account of Derrida's methodology. By referring to a typology, we will argue that Derrida insists upon the coimplication of general theories and specific contexts. We will make the suggestion, further, that the identification of new "types" expands the logic Derrida is interested in. The notion of "typology", on this reading, marks two important philosophical commitments: first, explanatory frameworks are ongoing projects, expanded by their different applications; second, such frameworks derive their value from their application within specific contexts, as opposed to their ability to predict forthcoming situations.

This will allow us, ultimately, to consider different moments in Derrida's thought as 'types': specific instantiations of a general logic, marked by the specificity of their context. This reading does not constrain Derrida's project to one unscathed, fixed logic, which disregards the peculiar effects of individual deconstructive interventions. Neither does it, however, look past the profound continuity apparent in Derrida's writings. The notion of a typology rather points to an expansive general logic instantiated in different contexts. It will allow us, in time, to consider how Derrida's late interventions differ from his early work without having to suggest a break or turn at odds with the recurrence of a certain logic. Indeed, while Derrida's late works are 
characterized by a set of new themes, we will argue that a more general deconstructive 'logic' is central to what is happening in these ethical and political texts. Ultimately, this interpretation of the Derrida's project as a typology will seek to insist upon the deconstructive project as a profoundly localized and context-based mode of thinking, moving away from general accounts and all-encompassing theories. It is here, perhaps, that we can understand Derrida as both a soixante-huitard and resistant to a wider political project such as Marxism.

This interpretation will arise out of two general moves. The first chapters will outline Derrida's early work on writing and communication to think through the function of general theories. There, our argument will be twofold: first, Derrida's work on the question of writing entails the impossibility of putting forth a fixed logic or conditions of possibility through the medium of writing. Second, Derrida's work on the constitution of meaning moves away from trying to uncover a fixed, preexisting unity, to rather focus an ongoing engagement with the specificity of particular contexts. Part of our work in this discussion will consist in attempting to reconcile a certain recurrent logic in Derrida's text, while paying attention to how it evolves across his writing.

In the third and fourth chapters, we will consider how Derrida's late works expand his 'logic' by introducing a new set of effects. There, building on Derrida's early work on communication, we will argue that what is at stake is neither reading Derrida's late works as a perfect repetition of his earlier logic, nor as the instantiation of a new logic. Rather, we will consider how the recurrence of a certain pattern allows us both to understand Derrida's late works in relation to his earlier thought and to observe its specificity. We will suggest, taking up a motif put forth in Signature Event Context, that Derrida's late works constitute a 'type'. This move does not reduce the late works to the logic of the early works, but rather shows how they build on the deconstructive logic and expand it. This will ultimately allow us to make the point that deconstruction is not inherently 'ethical' or 'linguistic', but rather disseminated into a number of new contexts whose specificity should be noted. Finally, this move will allow us to clarify some interpretive issues in Derrida's late works, and to suggest further horizons of intervention for deconstruction. 
Chapter 1:

Iterability, Repetition and Research 


\section{Iterability, repetition and research}

In Signature Event Context, Derrida is going to argue against the view that communication is merely the transference of a fixed, proper meaning. The notion of context will come to play an important role in this move, as Derrida will argue that what makes a word useful is its ability to be introduced into new contexts. This will come to entail that we cannot think of an all-encompassing, closed context of meaning. Rather, contexts of meaning are, on this interpretation, carried along by a repetition that never leaves meaning perfectly intact. This will lead to Derrida's important argument that communication is best understood as a form of dissemination, actively engaged in the constitution of meaning.

This kind of argument has at times been understood as a negative limitation of the capacity for fixed meaning ${ }^{1}$. Such an understanding of Derrida's project as a negative limitation of knowledge or identity might lead us to something like John D. Caputo's view on the status of Derrida's work:

Derrida does have a certain "philosophical idea" about language. One might even say he has a certain "theory", or a kind of theory, although that is a strong word implying mastery and a total overview and Derrida avoids it, usually preferring to speak of his "hypothesis," which is tentative, about which he is not sure, which he hesitates to bring up before this intimidating audience, etc. (Caputo 2000, 96)

In short, if deconstruction is interested in putting forth a certain undecidability or uncertainty, Derrida's own theories (or 'hypotheses') must also be conditioned by such structures. There is a similar problem in Signature Event Context: there, Derrida must account for the different ways in which his account of iterability will be actualized. Interestingly, Derrida's response to this problem is not to limit the scope of his claims; rather, he calls for a typology organizing different instances of iteration. In short, the emphasis here moves from a negative limitation of knowledge to an accumulative program of research.

To make these points in greater detail, we will make two moves in this chapter. The first is to clarify Derrida's account of communication and meaning in Signature Event Context. Our second move will introduce a line of questioning repeatedly at work in this thesis: how does

\footnotetext{
${ }^{1}$ Richard Rorty most famously puts forth this line of criticism (Rorty 1989).
} 
Derrida's own work deal with the problem of reinterpretation or writing? Through a close reading of a short passage in Signature Event Context, we will argue that Derrida calls for a new research program explicitly concerned with context. 


\subsection{Iterability in Signature Event Context}

Derrida opens Signature Event Context, a lecture given in 1971, with a quotation from Austin: "Still confining ourselves, for simplicity, to spoken utterance." (Austin 113) This opening plays on a number of levels. Derrida begins by communicating something that is not his own, by citing Austin's words. But Austin's words, here, have already been contaminated by Derrida's mark, who, in the act of translation, had to make up his own version of "Austin"2. These refashioned words undergo an additional displacement: while only a footnote in Austin's original text, they become the opening statement of Derrida's intervention. The beginning is corrupted: not quite Derrida's, not quite Austin's. Part of what allows Derrida to get away with this is a close concern for context: he will remind us, later on in the text, that philosophical citation has its own conventions. We should observe the way in which Derrida takes this up: he is both engaged in the performance of inherited discursive practices, i.e. philosophical citation, and attempting to expand or distort these practices. The beginning is thus corrupted one final time as Derrida puts the very concept of the norm into question: what is proper citation? Can we ever properly cite?

This theme of corruption is going to shape a certain movement at work within Derrida's text. While we will seek to expand this account beyond a critique of the fixed proper meaning, we might nonetheless begin by showing how this movement functions in the text. Derrida's account of language and communication, for instance, defines itself in opposition to an enlightenment conception of knowledge put forward by Étienne de Condillac. Derrida spells out the general lines of de Condillac's view in order to set the grounds for his criticism:

The history of writing will conform to a law of mechanical economy: to gain the most space and time by means of the most convenient abbreviation; it will never have the least effect on the structure and content of the meaning (of ideas) that it will have to vehiculate. (Derrida 1982, 312)

Derrida's argument will thus define itself against such moves, setting up a critique of 'objective' language and its depoliticization and objecting to a teleological account of the history of writing as optimization. Here, we should remark upon the features identified by Derrida in this account:

${ }^{2}$ Insofar as Derrida is of course writing in French, and must translate Austin's words. 
writing as an ineffective medium (which does not shape meaning), writing as a fixed structure, and a teleological history of writing. These features make up Derrida will refer to as the "narrow" account of communication.

To show how Derrida departs from this conception of language, we should develop two important notions in the essay: context, and iterability. The question of context appears early on in this essay. Here, Derrida is considering the question of communication which he will take up in his intervention:

It seems to go without saying that the field of equivocality covered by the word communication permits itself to be reduced massively by the limits of what is called a context (and I announce, again between parentheses, that the issue will be, in this communication, the problem of context, and of finding out about writing as it concerns context in general). (Derrida 1982, 310)

One of Derrida's important arguments in this essay is that while the narrow account of communication gives some credit to context in the question of communication and interpretation, its conception of context is inherently problematic. Derrida's claim is that the 'narrow' account of communication, extending from De Condillac to the thought of John Austin, depends on a conception of a closed context of meaning. We can see how such an understanding is able to downplay the importance of communication and writing by maintaining the fixity of meaning regardless of how it is communicated.

This intervention on the question of context has much to do with Derrida's account of another key term: iteration. Let us turn to the text to spell out this argument:

This iterability (iter, once again, comes from itara, other in Sanskrit, and everything that follows may be read as the exploitation of the logic which links repetition to alterity), structures the mark of writing itself, and does so moreover for not matter what type of writing (pictographic, hieroglyphic, ideographic, phonetic, alphabetic, to use the old categories). A writing that was not structurally legible - iterable - beyond the death of the addresse would not be writing. (Derrida 1982, 315)

Iterability structures writing, and is related to a certain 'logic' between repetition and alterity. What links this specific feature of writing to the concept of alterity? Why must writing extend beyond death, and what does death stand for here?

Consider the word 'red'. 'Red' is only a meaningful word if we can apply it in a number 
of different contexts. These contexts, in turn, contribute to what we mean by 'red'. Further, the context in which we use the term 'red' can never properly be closed off, since what makes it a meaningful term in the first place is its ability to be used in new contexts. This movement can be understood as an expression of 'iterability': it involves repetition and alterity insofar as (i) a term is repeated and (ii) the possibility of its repetition exceeds a particular context (and is thus 'other' to it). We will come to see, in a moment, why the capacity for re-inscription or repeatability takes the form of alterity and cannot be contained within repetition.

The point is not to say that meaning has no stability: it is rather to say that any such stability, at a minimal level, depends on the possibility of re-inscription. This possibility, however, gets in the way of a perfect stability or presence, since it entails that concepts are able to appear in different configurations of meaning. In simple terms, a word is meaningful because we can repeat it in all sorts of ways; but this implies that we might - through a repetition in a new context - come to reconfigure the meaning of a word. This move is both negative, by affirming the structural impossibility of a fixed language, and positive, by bringing forth the regenerative properties of meaning: the ability to make sense of new contexts or carry meaning across time. This capacity, for Derrida, extends beyond the terms of any particular context. The possibility of repetition is open-ended and indeterminate, or to use another formulation closer to Derrida, conditioned by alterity.

The question of a "secret language" is helpful to make this point insofar as it tries to separate alterity and repeatability. A secret language sets the parameters of its own repetition: only a few can interpret the language, which is to say that its repetition is limited and determined. Derrida turns to this question:

Let us imagine a writing with a code idiomatic enough to have been founded and known, as a secret cipher, only by two "subjects." Can it still be said that upon the death of the addressee, that is, of the two partners, the mark left by one of them is still a writing? Yes, to the extent to which, governed by a code, even if unknown and nonlinguistic, it is constituted, in its identity as a mark, by its iterability in the absence of whoever, and therefore ultimately in the absence of every empirically determinable "subject." This implies that there is no code - an organon of iterability - that is structurally secret. (Derrida 1982, 315)

The argument is that a secret language, whether linguistic or not, will operate based on the 
repetition of a set of signs. Part of what would make this secret language meaningful would the participants' ability to draw on a set of repeatable signs, gestures or sounds. The repeatability that allows for language to be used thus prohibits it from being secret insofar as the trace of the secret language must be reinterpretable: this is what gives it meaning in the first place. If a secret language tries to control the context of interpretation, Derrida's point is that what makes language meaningful in the first place is its ability to be recontextualized in different ways. Thus, a secret language must either give up on meaning, or operate using repeatable signs structurally exposed to reinterpretation. The impossibility of a secret language is another way to express the impossibility of closed contexts of meaning. In both cases, we see that the constitution of meaning and language depends on our ability to repeat signs in new or changing contexts.

Let us turn back to the two questions we raised in relation to these passages. Why does Derrida refer to 'alterity' in the context of this discussion on writing? And how is this alterity, alongside the question of writing, related to death? The opposition of repetition to alterity is meant to convey the sense in which the repetition of signs cannot be constrained by a given context. In order to constitute language, a sign must be reusable in different contexts: we must be able to apply old words to a new situation. The ability of signs to bring about entirely new configurations of meaning is conveyed by Derrida's use of alterity, insofar as this possibility extends beyond existing configurations of meaning. This is also what is at play in the question of death, insofar as the death of the author implies the end or modification of a certain context. The literary work of the author is thus characterized by its ability to extend beyond the context of the author's life, beyond a specific configuration of meaning into a number of other different ones a possibility conveyed by Derrida's use of 'alterity'.

The opposition of 'alterity' to 'repetition' can thus be seen as a way to address a certain problem. Derrida has made the point that language functions based on repetition: what makes a word useful is its ability to be applied to new contexts. These new contexts, however, imply distinct configurations of meaning. In this sense, trying to control the configurations of meaning in which a word can be repeated would be tantamount to negating its central asset: the ability to be applied to different contexts. Following the same line of reasoning, we see that the new configurations of meaning in which words can be applied cannot be limited to a law or set of operations since any such description would be attached to a previous configuration of meaning. 
Repeatability then entails alterity insofar as it implies the possibility to reconfigure configurations of meaning, and thus to express new meanings inexpressible in a previous context. In short, to limit future possibilities to an existing rationality would be to disregard the way in which meaning is constituted through inter-contextual repetition. 


\subsection{Derrida's Critique}

We have seen Derrida make a number of interrelated claims about language. The general point is that language functions around a changing system of repeatable signs. The further point is that this repeatability cannot be characterized which entails, in turn, that repetition is engaged with alterity, and that the system cannot be closed off. This follows from the claim that the repeatability of language implies the possible reconfiguration of signs in entirely new configurations of meaning, as for instance after an author's death. Finally, this alterity - seen in the inability to characterize or delimit the possibility of repetition - implies that semantic contexts, or configurations of meaning, cannot be perfectly fixed or closed off. Indeed, the repeatability of language, as characterized by Derrida, implies that the forthcoming repetition of a sign is always structurally able to undo any persistent definition. Our ability to use words in different ways implies that they can come to mean different things depending on their context.

Here, we can begin to outline Derrida's distinctly anti-Enlightenment project drawn in opposition to de Condillac. We should recall the latter's account of writing, which Derrida was criticizing. For de Condillac, writing was mere technique, efficiency, and had no role to play in the constitution of meaning. In this sense, writing did not reach any real concerns beyond those of spatial and technical efficiency. This comparison allows us to see how Austin fits right into the paradigm Derrida is arguing against. Like de Condillac, Austin views language as a passive medium which, when it operates properly, allows us to get things done. Derrida notes:

Austin's procedure is rather remarkable, and typical of the philosophical tradition that he prefers to have little to do with. It consists in recognizing that the possibility of the negative (here, the infelicities) is certainly a structural possibility, that failure is an essential risk in the operations under consideration; and then, with an almost immediately simultaneous gesture made in the name of a kind of ideal regulation, an exclusion of this risk as an accidental, exterior one that teaches us nothing about the language phenomenon under consideration. (Derrida 1982, 323)

Derrida's criticism is that Austin relegates the specific effects of writing and language on meaning to a mere accident. The point is that this kind of teleological account of writing systematically downplays its role within the formation of meaning and overlooks its specificities. More importantly, what Derrida shows is that these mechanistic and passive accounts of language are, in both cases, thought alongside a closed context of meaning. Here, we can begin 
to see the double disturbance opened up by Derrida's project: what is implied is not only a shift to writing as an area of concern, but also a restructuring of meaning in relation to writing.

Let us now turn to Derrida towards the end of his essay to see just how far his position departs from de Condillac and Austin: "One must [il faut] less oppose citation or iteration to the noniteration of an event, than construct a differential typology of forms of iteration." (Derrida 1982, 326) If the enlightenment move consists in downplaying the importance of writing and interpretation in view of truth and clarity, we can observe a full reversal at work here. Derrida suggests that these questions of citation and iteration - in short, the problem of language, repetition and interpretation - must instead be kept at the forefront. 


\subsection{Formulating the Project}

We have just seen Derrida evoking the possibility of a "differential typology of forms of iteration", and suggested that this entailed a reconfiguration of how we are to understand the formation of meaning. Let us turn back to this passage in order to unpack this suggestion: "One must [il faut] less oppose citation or iteration to the noniteration of an event, than construct a differential typology of forms of iteration." (Derrida 1982,326) What makes this passage so striking is that Derrida seems to actively take up two commitments in his earlier account account: the alterity of repeatability, and its relation to open contexts of meaning. Indeed, what is at stake here is not so much to identify whether or not writing produces effects; rather, one must now look at how writing is already producing effects.

We might begin by noting that the study of iteration, as presented here, is inherently multiple and divided. In other terms, Derrida extends his project beyond the search for a general logic of iterability: what is at stake here is not only to recognize the role of iteration (as a repetition against alterity), but to see how it is expressed in different ways. To situate this move, we should note that Derrida is responding to Austin. The latter conceives of different types of speech acts - citational utterances, in which we merely repeat something as it is, or performative speech acts, in which something happens through a speech act. This kind of thinking thus seeks to separate an ineffective repetition from a creative force; but Derrida's point is that both acts are structured by iterability. In simple terms, the common citation always involves a minimal displacement, and conversely, we can never really make anything happen without using old words. Yet Derrida does not want to reduce these different instances to one all-encompassing logic: rather, the project of a typology entails an organization of different configurations of iterability.

This offers a useful way to tie together Derrida's different moves. Insofar as contexts of meaning are open and signs are absolutely repeatable, Derrida points to an explicit focus on how we uphold configurations of meaning through certain arrangements of signs. This study, however, must be iterated on the terms of a certain context, in a certain language. Derrida's arguments in relation the structure of language entail that we cannot derive a fixed principle of iterability, insofar as the terms of such an account, as iterated, could not achieve the stability 
required to serve as a defining causal force. Given these commitments, it is interesting to note Derrida's formulation of a 'typology of forms of iteration', where a typology evokes both a systematicity and an active reconfiguration open to change. In the use of types, we see an active move of classification open to change. This is coherent insofar as Derrida has shown that meaning - and consequently, the meaning of a theory of meaning - depends on the possibility of re-inscription and reinterpretation.

The overall move of this passage, and of Derrida's typology, thus seems to extend beyond the unsettling of fixed categories. It appears to call, further, for the identification of new configurations of meaning as yet unidentified. In simple terms, the point seems to consist not only in 'downgrading' intentionality by subjecting it to the structure of writing, but in formulating how this relation manifests itself in different contexts. In the following sections, we will turn to the relation between Derrida's typology and the notion of intentionality. While this discussion might seem rather theoretical at first, our reader should keep its importance in mind. The exposition of the relationship between intentionality and iterability will, in time, allow us to make two points. First, the structure of iterability does not depend upon an intentional subject: the question of writing extends beyond the subject and her individual capacity to construct meaning. Second, and building on this point, the appearance of an intentional subject within the discussion of iterability speaks to Derrida's close relation to context. The explanatory power of a theory such as that of iterability depends on its intrusion into an established context: for instance, that of communication, in which one cannot simply look over the subject. 


\subsection{Intentionality and Typology}

We should clarify Derrida's relationship to intentionality, as it explicitly comes up in the account of typology we have been following. A little earlier in the text, intentionality is brought up in relation to Austin's account of the performative. Here, Derrida's general argument is that intentionality, as the involvement of a self-conscious subject within a performative speech act, is used by Austin to contain any 'remainder' and maintain closed contexts of meaning:

Austin's analyses permanently demand a value of context, and even of an exhaustively determinable context, whether de jure [en droit] or teleologically; and the long list of "infelicities" of variable type which might affect the event of the performative always returns to an element of what Austin calls the total context. (Derrida 322)

Derrida, throughout this essay and at many further points in his work, is concerned with this move that attempts to reduce alterity (within a relation of repetition-alterity) to a mere mistake. This move, as Derrida shows through Austin, is two-fold: it implies not only the containment of this remainder, but a concurrent attempt to close contexts of meaning. In short, to characterize the contingent as a 'mistake', Derrida suggests, is to reclaim a certain control over a scene of interpretation. This what Derrida sees Austin up to here, as the identification of infelicities mistakes - allows for their resolution within a fixed context of meaning.

An even stronger manifestation of this move, Derrida argues, occurs in the question of intentionality:

(...) the long list of "infelicities" of variable type which might affect the event of the performative always returns to an element of what Austin calls the total context. One of these essential elements - and not one among others - classically remains consciousness, the conscious presence of the intention of the speaking subject for the totality of his locutory act. Thereby, performative communication once more becomes the communication of an intentional meaning, even if this meaning has no referent in the form of a prior or exterior thing or state of things. This conscious presence of the speakers or receivers who participate in the effecting of a performative, their conscious and intentional presence in the totality of the operation, implies teleologically that no remainder escapes the present totalization. (Derrida 322)

To be clear, Derrida is criticizing Austin for the centrality of this intentional subject. Yet this centrality is crucial to the latter's system: intentionality, as the implication of a subject within a speech act, contains the many possibilities for error. The various things a person might do as a 
free agent allows Austin, Derrida will go on to argue, to contain alterity to a mere set of errors. This is in fact a very simple point: Austin wants to contain the problem of interpretation to the subject. Should something go wrong in the movement of communication, we might simply point to a specific error made by the subject. The intentionality of a speech act - the fact that someone consciously utters it - allows us to blame the speaker for possible misinterpretations.

The next appearance of intentionality occurs a little after the passage we have previously considered. There, Derrida writes:

Thus, one must less oppose citation or iteration to the noniteration of an event, than construct a differential typology of forms of iteration, supposing that this is a tenable project that can give rise to an exhaustive program, a question I am holding off on here. In this typology, the category of intention will not disappear; it will have its place, but from this place it will no longer be able to govern the entire scene and the entire system of utterances. (Derrida 326)

The move here is to reframe intentionality as one form of iteration, a code that becomes itself as it is continually repeated. As we have seen, the centrality and persistence of the intentional subject allowed for closed contexts of meaning in Austin's account, since accidents could be accounted for on the grounds of the subject. Derrida's move is then twofold: first, this characterization of intentionality as iterated entails that it can no longer be fully present, since iterability implies the rupture of repetition (presence) / alterity (absence):

Given this structure of iteration, the intention which animates utterance will never be completely present in itself and its content. The iteration which structures it a priori introduces an essential dehiscence and demarcation [une brisure essentielle]" (Derrida 1982, 326)

By arguing that intentionality is iterated, Derrida tells us that whatever we take to constitute an "I" arises within a repetition imposed against the possibility of its repetition: alterity. What this entails is that our experience of the "self" is expressed in signs repeatable across contexts, which means that we might come to rethink our self-understanding, or the decisions we make, at different moments or in different contexts. Derrida's mention of a "brisure essentielle" gives expression to this double move: the radical rupture opposing repetition to alterity, and the collapse of an essential account of intentionality.

This characterization of intentionality as iterated should be thought of alongside a critique 
of Austin's commitments to closed contexts of meaning. Derrida writes:

Especially since this essential absence of intention for the actuality of the statement, this structural unconsciousness if you will, prohibits every saturation of a context. For a context to be exhaustively determinable, in the sense demanded by Austin, it at least would be necessary for the conscious intention to be totally present and actually transparent for itself and others, since it is a determining focal point of the context. (Derrida 1982, 327)

Here, the move is quite clear: insofar as intentionality is itself iterated, constituted by a set of repetitions which each time bear the chance of instability, the subject can no longer uphold the entire system. In other terms, a subject cannot account for every possible mistake if such a subject is constantly in the process of becoming itself. 


\subsubsection{Loizidou on Intentionality}

In a study entitled Judith Butler: Ethics, Law, Politics, Elena Loizidou considers Derrida's account of iterability. Given that iterability plays an important role in Butler's own work, as in, for instance, Bodies That Matter, clarifying this logic in Derrida's work is a pressing task. Loizidou's suggestion is that Derrida's notion of iteration presupposes a fixed, pre-linguistic conception of the subject. This is an important move in relation to our project; insofar as our argument concerns the open-endedness of a deconstructive logic, we should think through the issue of whether intentionality constitutes a fixed feature of such a logic. Loizidou writes:

On the one hand, Derrida is urging the creation of a different typology of forms of iteration, one that does not set up citation in conflict with the performative. But, at the same time, he insists that intention (the 'I' behind the speech act) remains central to this new order of forms of iteration. Derrida is confident that in such a situation intention will not be able to organise the scene of iteration but just be present to it. (Loizidou 2007, 34)

Here, Loizidou rightly recognizes Derrida's typology as the implementation of a general framework of iterability, in which the performative and the citational are understood as instances of repetition. This is a reformulation of Derrida's simple point that meaning implies a certain repetition, and as such that the invention of a meaningful concept implies a repetition or reconfiguration as opposed to an act of pure creation. Yet it is not immediately apparent how, as Loizidou claims, "that intention (the 'I' behind the speech act) remains central to this new order of forms of iteration" (Loizidou 2007, 34). Two things should be noted here: first, Loizidou implicitly equates the intention with a subject behind a speech act. Second, the very passage quoted to make this point against Derrida speaks of intentionality as "no longer be able to govern the entire scene and system of utterance" (Derrida 1982, 326).

We should in fact question whether Derrida's logic prioritizes a certain 'natural' subject. This would be damaging to the project of a typology, which would remain linked to a certain humanist project, one that Loizoudou suggests acts as a trace of enlightenment thinking. It would contribute to a certain definition of Derrida's project as a negative limitation of human cognition. The problem at hand, then, is twofold: first, it would concern the implicit positing of an indeconstructible subject, which is to say of a fixed subject whose meaning or stability is defined outside of a movement of repetition and alterity. Second, it would entail that the constitution of meaning is dependent upon this indeconstructible subject, which would limit Derrida's projects 
in all sorts of ways. Of Derrida's typology, Loizidou writes: "his insightful invitation to rethink the terrain of forms of iteration is unfortunately problematic. Derrida fails to see that the 'doer' is an effect of the performative and the citational" (Loizidou 2007, 34). In order to make this point, Loizidou needs to reaffirm a distinction that was previously overlooked, as she, in one broad stroke, spoke of the "intention (the 'I' behind the speech act)" (Loizidou 2007, 34). Yet if, as Loizidou argues, Derrida fails to see that the 'doer' is conditioned by iterability, then we must conceive of the 'doer' and intentions as separate. If we think of them together, the 'doer' would come to be conditioned by the iterability that Derrida argues is at stake in the question of intentions, which to say that no 'subject' would arise outside of a repeated configuration of signs.

Loizoudou's next move complicates the relation between subject ('doer') and intention: "Derrida fails to see that there is no intentional subject (even if his intentions do not organise the terrain of speech happenings) behind the speaking." (Loizidou 2007, 34) The criticism laid out here seems to make two moves: first, Loizidou acknowledges Derrida's displacement of intentionality as "no longer (...) able to govern" (Derrida 1982, 326), conveyed here as Loizidou writes: "(even if his intentions do not organise the terrain of speech happenings)" (Loizidou 2007, 34). Second, Loizidou suggests that Derrida leaves an "intentional subject (...) behind the speaking"(Loizidou 2007, 34). In short, the criticism is that Derrida posits a prelinguistic subject, a subject behind iterability, which is to say, immune from such a logic. If this were the case, Derrida's typology would only show that there is more at work than intentionality, while leaving the subject as a permanent feature of every scene of iteration.

This move would be problematic for a number of reasons, one of them being that it would reproduce the very issue Derrida sees in Austin: a subject central to communication. Yet it is not clear how such a prelinguistic subject manifests itself in Derrida's account. Here, we should refer back to Derrida's previous comments on intentionality: "The first consequence of this would be the following: given this structure of iteration, the intention which animates utterance will never be completely present in itself and its content." (Derrida 1982, 326) The point here is quite clearly that a subject's intention or involvement in relation to an utterance is itself iterated, which is to say that the subject's intention becomes itself at every repetition (or at every moment as a subject). At another level, this can be read as the claim that our intention to say something can always be rethought, or reconsidered, hence Derrida's image of a "structural 
unconsciousness" (Derrida 1982, 327).

Loizidou's final take on Derrida's project rephrases the problem with a different emphasis:

While this interpretation of Derrida's citational utterance may appear ungenerous, since his aim was precisely to invoke a different 'I', an 'I' that is constantly in deferral, it still remains the case that it is impossible, at least in this particular text, to understand his ' $I$ ' as an effect of the doing. Derrida's desire is to see this 'I' displaced, unable to organise the field of iteration in reference to itself, but paradoxically what is sustained (at least in Limited Inc) is this precise 'I' as the organiser of iteration. (Loizidou 2007, 34)

Here, Loizidou recognizes that the 'I' is caught up in deferral, which is to say, never fully determined. Yet if this is the case, if intentionality and the subject are both constituted by deferral, then neither can arise outside of a certain repetition or iteration. The point to make here is that the deferral mentioned in Loizidou's text is not a mere feature of fixed, natural entities: rather, it arises as an effect of iteration. If the ' $\mathrm{I}$ ' is, as Loizidou claims, is in deferral, then it must in fact be an ' $\mathrm{I}$ ' that is an effect. The status of the ' $\mathrm{I}$ ' as an effect implies that it is produced within a semantic context open to change, which in turn makes it impossible to hold the subject as the central, grounding element of a system.

One might argue, finally, that Derrida only puts a part of the 'I' in deferral. A certain reading of Loizidou's critique might suggest this, although it would demand a return to the previous distinction made between a fixed subject and iterated intentions. The argument could then be that what is deferred is the status of iterated intentions, but not the centrality of the subject within such iterations. In short, a pre-linguistic subject would, through repetition, formulate different finite and deferred intentions. The question, then, is the following: can we conceive of an iteration without intention? Or of an iteration without a subject? When Derrida suggests that intention "will have its place" (Derrida 326), are we speaking of a natural place, or a provisional place?

Let us recall the general lines of Derrida's argument. His point that we cannot hold someone accountable for all "errors" in communication, insofar as this subject's intentions, what she meant to say or do, is iterated within a series of repeatable terms: "I want to $x$ " or "My intention is to $y^{\prime \prime}$. We use expressions like this because they are useful in clarifying what is 
happening; but conversely, what makes such expressions useful is that we can repeat them in different situations and at different moments. This view of language entails two things: first, the terms used to characterize our initial intention might come to mean something else to us, or we might have a different view of our intention to $x$ in different periods of our lives. Second, the incompleteness of such intentions - the fact that they can be taken up and reinterpreted in a number of a ways - entails that the context of their definition is structurally open.

To conclude, we will attempt to address the last concern we laid out in relation to Loizidou's account: the dependence of intention on a fixed subject in the form of the 'I'. By claiming that intentionality is iterated, Derrida is making the point that it is expressed - or made sense of - through the repetition of a certain configuration of signs. What this entails, however, is that every part of the expression "I want to $x$ ", or every facet of an identifiable phenomenal experience of an intention in a speech, is open to reconfiguration. Here, Derrida is primarily interested in the reconfigurability of the intention itself, which makes sense in relation to the context of his intervention. Derrida is trying to destabilize Austin's containment of alterity into a list of "infelicities", and given that such infelicities often have to do with a subject's intentions, the quickest path for Derrida is to reveal the instability of such intentions. This does not, however, point to intentionality as the beginning of our constructed selves.

This disagreement might come down to the passage taken up by Loizodou. There, Derrida tells us that intentionality will have its place in the typology. This might, in a certain sense, seem like Derrida holding on to the notion of intentionality, not wanting to do away with it or fully expose it to deconstruction. Yet the aim is quite different. We should recall that Derrida begins his discussion of the typology by suggesting that we should not oppose citational to performative acts, which is to say that any act of speaking involves a minimal repetition of words and signs. We should rather, within this typology, consider the different configurations of repetition at work in formation of meaning. " In this typology," Derrida reassures the reader, "the category of intention will not disappear; it will have its place, but from this place it will no longer be able to govern the entire scene and the entire system of utterances " (Derrida 326).

The point might not so much be to advocate for the centrality or persistence of an intentional subject, as Loizidou seems to suggest. Rather, this qualification might simply serve to 
show that Derrida's typology can account for different effects of consciousness or intentionality. The point Derrida is making here is that his constructivist account does not reduce the affective or lived component of certain experiences of repetition. It does not negate what one might identify as the experience of performativity or intentionality to a mere standardized act of repetition. Rather, it recognizes such experiences as forms of iterations, or repeatable configurations of repetition and alterity. The preservation of intentionality here has more to do with a certain realism, insofar as our experiences and use of speech are marked by intentionality: but it does not legislate or naturalize the constitution of intentionality or an intentional subject. The uptake of this move is that Derrida is both able to account for intentionality, and to think beyond it.

This chapter has thus made two moves: first, we considered Derrida's account of iterability and meaning in detail. Second, we considered how Derrida called for a typology, which is to say a contextual study of how a general logic is instantiated. We made the further point, through Loizidou's commentary, that such a typology would not be bound to intentionality. In other terms, the point is not to observe how $I$ experience different contexts, but rather how different contexts frame this ' $I$ ' and make it more or less central to a speech act. Nonetheless, the project of a typology necessitates a further clarification that we will take up in the coming chapter: how are we to define a 'form of iteration'? What distinguishes the different types contributing to Derrida's projects? 
Chapter 2

Quasi-Transcendental Forms of Iteration 


\section{Quasi-Transcendental Forms of Iteration}

We have seen how Derrida attempts to deal with a certain problem in Signature Event Context. On the one hand, Derrida is interested in applying a general structure of iterability to speech acts. Contra Austin, the argument is that both the ordinary experience of 'citational utterance' and the active engagement of a 'performative' speech act are iterated: both rely on a structure of repetition and alterity. The simple point is that there is neither an ineffective repetition that leaves its content intact or an act of pure performance or creation. This point will come back at a number of places in Derrida's thought. One potential concern with this move is that it cannot simply provide an undifferentiated account of rather different situations: in other terms, it will not do to claim that the experience of a citational utterance and a performative speech act come down to the same relation of iterability. Rather, to keep his account in line with the different ways in which iterability comes to frame a situation, Derrida posits the project of a typology of the forms of iteration.

Here, Derrida could have simply accounted for the multiplicity of different outcomes by making a claim such as "the conditions for any speech act are..." Indeed, the move here could have consisted in positing a fixed general logic, and arguing that it delimits the space of possibility in which it operates. From such a standpoint, there would be no need to investigate local instantiations of the logic since they would be contained, at a prior level, within a wider argument or condition of possibility. Yet Derrida's move is rather different: it involves looking at specific, concrete situations to see how his logic operates within them. This raises two important questions: how are such 'forms' of iteration identified, and how do individual 'forms of iteration' relate to the wider logic?

This is an interesting problem because it operates, at a certain level, throughout Derrida's entire work. Indeed, as we will come to show, the recurrence of a certain 'logic' in Derrida's work calls for a closer look at the relation between a wider theory and its specific instantiations. In other terms, we will suggest that the problem of the relation between 'iterability' and its specific instantiations is analogous to the relation between a 'deconstructive logic' to its specific appearances. Drawing on this move, we will consider how Derrida uses the concept of the quasitranscendental to characterize his interventions, in order to finally suggest that this concept can 
clarify the question of forms of iteration.

In the first moment, we will consider the problem of 'forms' or 'types' of iteration, turning to Julian Wolfreys' interpretation of the passage we have previously considered. In the second moment, we will turn to Derrida's much later Faith and Knowledge (1991) to consider how it frames the 'quasi-transcendental' and points to the recurrence of a certain deconstructive logic previously mentioned by Derrida. In the third section, we will consider a recent account of the quasi-transcendental by Sina Kramer. There, we will build on her notion of a temporality of the quasi-transcendental and suggest that Derrida's remarks in Faith and Knowledge are consistent with Kramer's view, but can add further clarifications. To conclude, we will attempt to relate the question of the quasi-transcendental and that of a typology of iterability. 


\subsection{On Types}

We have suggested that forms of iteration would consist in different configurations of the relationship between repetition and alterity: the repetition of different codes, or a repetition operating in different ways (i.e. words, images, movements). Let us recall Derrida's problem: he wants to remain attuned to the various experiences of iteration without reducing them to a single framework. Thus, as we have seen, a typology of the forms of iteration is put forth. It remains to be seen exactly what the status of such forms is, and whether we can arrive at a sufficient or final account. Let us turn back to Derrida to explore this question:

One must less oppose citation or iteration to the noniteration of an event, than construct a differential typology of forms of iteration, supposing that this a tenable project that can give rise to an exhaustive program, a question I am holding off on here. (Derrida 1982, 326; emphasis added)

There is something odd about this passage. Why would Derrida even grant the possibility of an exhaustive program of iterability? Would this not imply a return to a closed context of meaning? Let us turn to a longer passage to take up this problem:

Not that citationality here is of the same type as in a play, a philosophical reference, or the recitation of a poem. This is why there is a relative specificity, as Austin says, a "relative purity" of performatives. But this relative purity is not constructed against citationality or iterability, but against other kinds of iteration within a general iterability which is the effraction into the alledgedly rigorous purity of every event of discourse or every speech act. (Derrida 1982, 326)

There are different types of iterability: in reciting a poem, Derrida's argument goes, one is aware of the dependence of a situation or its meaning upon a repeatable code (the poem). Yet in other contexts, such as when we express a vivid image in great detail, this relation to repeatability is concealed. These experiences, akin to Austin's account of the performative, come to downplay the part of repetition and citation. In a poem, we are aware of repetition; in moments of tumult or surprise, each instant can appear absolutely singular (although its 'appearance', as a repetition, undoes such a singularity). Derrida's point appears to be that we can account for the difference between such experiences by delimiting 'forms' of iteration.

The question of how we are to identify such a form demands clarification and is further complicated by certain ambiguous passages in Signature Event Context. For instance, Derrida 
speaks of "other kinds of iteration within a general iterability" (Derrida 1972, 389). In fact, while Alan Bass translates "espèces" as "kind" here, we should also read it as "species' of iteration. What must be questioned, then, is how we should think of these forms of iteration that we have tried to spell out, and how they might be related to a wider category of iteration. Interrogating the status of a 'general iterability' is here useful to establish its relation to particular kinds. General iterability is, on Derrida's account, a condition of meaning: a claim that is not iterable - i.e. repeatable - cannot have meaning insofar as this repeatability is the condition of its interpretation. For this very reason, one might suggest that the unconditionality of iterability as a condition of possibility cannot be grasped by language. This is precisely where language would fail, insofar as it marked by the conditionality of a coming future. This move, however, holds up the kind of dualism between sign and meaning that Derrida has been arguing against. To claim that "there is" a general iterability which language grasps with fluctuating success is to disregard Derrida's insight that meaning is disseminated, i.e. carried along by changing repetitions. Thus, the question of "general iterability" must remain structurally open insofar as it is meaningful. Further, the idea of an 'exhaustive' topology of iteration which Derrida evokes appears concerning, insofar as the identification and repeatability of such iterative processes would, according to this very argument, entail their dissemination. In simple terms, to claim that there are a number of ways of speaking would be to ignore the manner in which such ways become themselves again at every moment. In spite of Derrida this time, we can show the strength of his argument on context: the favoring of iteration over fixed essence entails an open context of repetition. So long as a principle of iterability is itself iterated, it exists within an open context resisting any 'exhaustive' typology.

There is, we would argue, a way to reconcile Derrida's seemingly essentialist claims with the condition of iterability. On this reading, we might 'iterate' different instances of iterability. And we may well, further, adopt a certain order of classification to make sense of such instances. Given a set of such processes, we could derive an understanding of a 'general' form of iterability. Yet we must note the specific generality of such an iterability. Two features stand out. First, this general class must be iterated, which means that it must be stated within a repeatable language open to change. Second, the open-endedness inherent to the repeatability of such a general class entails that it cannot be an atemporal condition of possibility. This general class would merely identify a set of effects of such a condition and re-inscribe or reconfigure such 
effects within a new context. As always, this act of repetition through classification (repeating 'as' category x) would come to shift the context as a whole. Lastly, the application of a 'general logic' within any new context would risk unsettling the meaning of any such logic, which is to say that the definition of any such logic can be affected by new contexts of interpretation. 


\subsection{Typology and Stability}

To clarify this point, let us turn to Julian Wolfreys' interpretation of this passage, which raises some important questions:

Derrida's notion of a differential typology is proposed around the active re- inscription, the rereading of the notion of intention, whereby, as is well-known, intention remains to be considered but without that consideration assuming that intention can govern or master all utterances. (Wolfreys 2003, 85)

One should note the prominence that Wolfreys gives to Derrida's remarks on intentionality. As we have argued, this can certainly be read as an effect of Derrida's suggested typology. Yet we should keep in mind, beyond the destabilization of intentionality as a form of iteration, the opening up to new forms of iteration. We can begin to bring out this point by returning to Wolfreys:

Furthermore, the very conceit of the differential typology is itself unstable, if not performative and undecidable, for it operates around the possibility of imagining the speech ungovernable by any typology that would remain programmatically constant across any range of utterances. (Wolfreys 2003, 85)

The qualification of Derrida's typology as a somewhat idealistic project - "unstable, if not performative and undecidable" (Wolfreys 2003, 85) - should be thought alongside its role as a critique of intentionality. Let us clarify. Derrida is saying that we should examine how meaning is constituted by repetition and alterity. In the case of intentionality, this entails that the intentional subject is downgraded from the grounding element of a structure to one type of iteration or repetition. The 'I' moves from present, immovable center to a changing, repeated sign. On Wolfrey's account, Derrida's imagined typology is bound to undecidability insofar as it attempts to determine an open-ended multiplicity of determinative processes. In other terms, to assume iteration in the way that Derrida speaks of here entails an open-ended, changing configuration of iterative processes (since the relationship between repetition and alterity continually unfolds in new contexts). Thus a typology, Wolfreys rightly notes, cannot be final insofar iterability constantly takes place in new configurations of meaning. This is similar to the point made in the previous section.

We can illustrate this move by noting that even if we identify individual processes of 
iterability - for instance, biological or economic frames of iteration as vocabularies (linguistic, visual, etc) and grammars shaping the possibility of meaning - such forms of iterability always arise in peculiar contexts, which in turn shape the effects and definition of such an iterability. Thus on Wolfreys' account, any typology is bound to instability insofar as the dissemination of iterative processes precludes the identification of any general 'type'. Here, however, we should ask what kind of 'type' Wolfreys is after, and how this demands shapes the possibility for any typology. Is the implication that the stability of a type lies in its ability to fully account for future events?

For indeed, if we turn back to our discussion of types, Wolfreys' account would seem to remain attached to a certain conception of 'types' as present and determinate. This commitment would hinge upon the association of 'stability' with the identification of a type immune from contingency. As we have seen, this is precisely what is stake in Derrida's own account, insofar as he himself would seem to search for a 'general' constitutive type. The strength of Wolfreys' argument, contra Derrida, is that he recognizes the inherent dissemination of iterative processes. Thus, unlike Derrida, Wolfreys dismisses the idea of an 'exhaustive' topology of forms of iterability. Like Derrida, however, Wolfreys is aware of the threat underlying this impossibility, particularly in a context of research seeking 'determinate' truth. Whereas Derrida responds to such a threat by deferring it (namely, by leaving open the possibility of an exhaustive typology), Wolfreys faces head on the problem of dissemination that, according to his account, entails the instability of any proposed typology.

We might however question whether this opposition of 'stability' and 'instability' does not depend upon an old system of present, fully determined meaning. Is the entailment not that 'stability' is free of contingency, and that the contingency inherent to the identification of any 'type' precludes such a stability? The deconstructive argument, however, entails that any such 'stability' would be tantamount to meaninglessness. More so, such a stability would be wholly unthinkable insofar as it would be unrepeatable, and thus unidentifiable. As Derrida has shown, the impossibility of such a 'stability' is also the condition of any meaning for any stability. In somewhat of a reversal, we come to observe that the meaning of 'stability' depends upon a constitutive contingency. What is 'stable' is not unchanging; it is, rather, what persists across different contexts. 
For Wolfreys, the point is not that processes of iterability change too much and thus preclude a 'stable' type. The point is rather that insofar as such processes change (which they necessarily do, through a disseminating repetition), we structurally cannot achieve a stable typology of iterability. This opposition of contingency and stability seems to depend upon a somewhat un-deconstructive account of stability. More problematically, it exposes the deconstructive argument to a set of criteria wholly outside of its scope. This move conveys the deconstructive project as a constant falling short of metaphysical ideals ("unstable", "undecidable"), without insisting upon Derrida's wider point that such ideals are inherently selfcontradictory. If we take the deconstructive argument seriously, there is no reason to oppose stability to contingency. In fact, as we have seen, stability itself entails a constitutive contingency, which is to say that something can only be stable if it can be repeated and thus bears the chance of instability. An affirmative typology of iterability could thus be 'stable' insofar as its repetitions (i.e. its application) maintain some continuity despite other possibilities. In other terms, particular instances of iterability could fall under a 'stable' category that, while not atemporal or constitutive, identifies general patterns of iteration and thus reconfigures the context as a whole.

In short, we have made the point that iterability entails a different relation to general theories. On this account, the meaning of a theory is not preserved but rather disseminated in new contexts. This further evokes, we have suggested, a new understanding of "general iterability" as itself iterated, which is to say as a concept which remains at stake and is not fully determined. The meaning of such a "general" logic would thus be closely tied to the ways in which it is applied, and to the context in which it arises. From this angle, Derrida's typology of iterability indicates a certain co-implication or co-constitution at work in the relation between a general theory and its specific instantiations.

Our interest will be to think this problem at a wider level in Derrida's work. There, we might say, one should not oppose the repetition of a certain deconstructive logic from the eruption of a new deconstructive logic: rather, one could view the various events of deconstruction as a typology of the forms of the deconstructive logic - and, given that such a logic is conveyed by iteration, the relation between Derrida's different works could itself constitute a typology of the forms of iteration. In the following sections, we will closely consider 
the notion of a 'deconstructive logic' and its relation to specific contexts through Derrida's argument of the 'quasi-transcendental'. 


\subsection{On a Certain Deconstructive Logic}

In this section, we will consider shared structural features apparent in different moments of Derrida's work. This type of exercise demands qualification given Derrida's vast number of published works. Here, our claims will only concern the similarities between Signature Event Context and Faith and Knowledge. This work will help us clarify, in a later chapter, the relation between Derrida's early work and the later Of Hospitality, and attempt to address a certain facet of the "logic which links repetition to alterity" (Derrida 1982, 315) previously evoked by Derrida.

Faith and Knowledge, initially published in 1996, is a proceeding from a conference on religion held in 1994. As in the first chapter, we should keep in mind the way in which Derrida's text initially constitutes a certain intervention, a performed text at a conference meant to generate proceedings (Derrida, in the text, highlights that he has already agreed to publish his intervention). Here, Derrida brings in the notion of the "quasi-transcendental" as he unfolds his argument on what he will go on to call the "two sources" of religion:

We will not be able to undertake here all the analyses required by distinctions that are indispensable but rarely respected or practised. There are many of them (religion/faith, belief; religion/piety; religion/cult; religion/theology; religion/theology; religion/ontotheology; or yet again, religious/divine - mortal or immortal; religious/sacred-saved- holy-unscathed-immune- heilig). But among them, before or after them, we will put to the test the quasi-transcendental privilege we believe ourselves obliged to grant the distinction between, on the one hand, the experience of belief (trust, trust worthiness, confidence, faith, the credit accorded the good faith of the utterly other in the experience of witnessing) and, on the other, the experience of sacredness, even of holiness, of the unscathed that is safe and sound (heilig, holy). (Derrida 2000, 55)

The most straightforward way to bring out the similarities between this passage and Derrida's earlier work is to consider the question of opposition. Here, Derrida lists a number of oppositions within the semantic field of religion as potential sites of inquiry. In relation to language, we might point out two features here: first, the establishment of a context, and second, the relationality between the terms in such a context, emphasized by their opposition in Derrida's formulations (for instance, "religious/divine"). If we follow the argument laid out in the previous chapter, the differences between such terms cannot be definitively settled, since the context in which they arise is open-ended. The destabilization of differences thus opens up the context of their interpretation and is followed by a third moment, in which Derrida hones in on a specific 
opposition.

We should then keep in mind the way in which Derrida acknowledges a certain context of interpretation, as if to tell us that he is not starting from two abstract terms that he will apply to a situation. Derrida is rather working from within; he writes:

But among them, before or after them, we will put to the test the quasi- transcendental privilege we believe ourselves obliged to grant the distinction between, on the one hand, the experience of belief (trust, trust worthiness, confidence, faith, the credit accorded the good faith of the utterly other in the experience of witnessing) and, on the other, the experience of sacredness, even of holiness, of the unscathed that is safe and sound (heilig, holy). (Derrida 2000, 72)

The prior list of oppositions began to point to a certain semantic context through a set of oppositions. Here, however, a more pronounced irresolvability appears between belief and the sacred. Belief is, on Derrida's account, associated with faith and openness, while the sacred involves stability and repetition. This opposition replicates (unfaithfully, as will come to see) features of what Derrida calls the 'logic' of alterity and repetition at work in the question of writing. We can continue to observe such a general logic at work as, a few lines later, Derrida's thesis on the two sources of religion is introduced: "These comprise two distinct sources or foci. 'Religion' figures their ellipse because it both comprehends the two foci but also sometimes shrouds their irreducible duality in silence, in a manner precisely that is secret and reticent." (Derrida 2000, 72) To be clear, Derrida suggests that religion, as a meaningful thing to which we can refer, is constituted by the movement between these two irresolvable sources - one having to do with openness and indeterminacy, the other having to do with identity and repetition. The relation to Derrida's argument on meaning as the co-implication of repetition and alterity cannot be overlooked in relation to this claim.

Building on this point, the preceding passage is also helpful in its use of "ellipse", a recurrent term in the later Derrida, most prominently in Rogues (2002). Matthias Frisch makes the important point, in "Taking Turns: Democracy to Come and Intergenerational Justice" (2011), that the original term "ellipse" has two connotations in French: the contraction used to indicate an omission when citing a text, and the figure of an ellipsis. An ellipsis, as a geometrical figure, has two foci, which makes it particularly relevant to Derrida's thesis in this context, as he holds repetition and alterity to be both co-implicated and distinct. The image of the ellipse entails 
the further point that a circle is merely a special case of an ellipse, in which one focal point conceals the other. Let us consider the implication here: Derrida is saying that the reduction of religion to either belief or the sacred rather entails that the other focal point has been looked over, contained or dissimulated. The circle is merely a dissimulated ellipse. In fact, this is very much the same point made in the discussion of a typology, when Derrida suggests that one should not oppose citational utterances to performative statements. What is at stake, as in the elliptical movement of religion, is that there is no perfect repetition or absolute invention, but rather moments in which either repetition or alterity plays a more important part in a scene.

The metonymy of the ellipse clarifies the irresolvability of the relation explored in another sense of "ellipse" as a movement of citation: (...). The ellipse is a trace of what exceeds the text: what is left out or put to the side. As a figure of language, it thus signifies both the authorial intervention within an act of citation or writing and the possibility of its reinterpretation based on what has been left out or what is to come. The ellipse points to both a determinate arrangement, a choice of organization in an act of citation and the possibility to challenge such an act. It insists that our very ability to intervene within a text arises alongside the possibility of reinterpretation. This relation between repetition and alterity so aptly conveyed by the ellipse thus persists from Signature Event Context to Faith and Knowledge, and allows us to suggest, in at least these texts, the recurrence of a certain logic of repetition and alterity already pointed to by Derrida.

Let us return, one final time, to the passage with which we started in order to see how the quasi-transcendental fits in to this recurring elliptical structure:

But among them, before or after them, we will put to the test the quasi- transcendental privilege we believe ourselves obliged to grant the distinction between, on the one hand, the experience of belief (trust, trust worthiness, confidence, faith, the credit accorded the good faith of the utterly other in the experience of witnessing) and, on the other, the experience of sacredness, even of holiness, of the unscathed that is safe and sound (heilig, holy). (Derrida 2000, 72)

We should note that the quasi-transcendental status of Derrida's intervention has much to do with the lexical field he is operating in. The many words, meanings and oppositions constituting 'religion' allow Derrida, somewhere "among them, before or after them", to put forth a further distinction. The fact that Derrida is operating within this particular context, and not simply 
applying an external logic, entails that his relation to these terms is ambiguous. Derrida does not simply come 'after the fact' and observe fixed relations. Neither does he purely come 'before' by offering conditions of possibility. In Signature Event Context, we saw that the kind of communication Derrida is engaged in at this conference on religion - communication in both its English sense and the additional meaning, in French, of an academic presentation - cannot leave a context of interpretation intact. In this sense, Derrida is before and among these oppositions, since he is both using them and shaping the possibility of their future reinterpretation.

This formulation might appear odd: "among them, before or after them, we will put to the test the quasi-transcendental privilege we believe ourselves obliged to grant the distinction between..." (Derrida 1982, 72). The sentence in French is difficult to translate: "Mais parmi elles, avant ou après elles, nous mettrons à l'épreuve le privilège quasi-transcendental que nous croyons devoir accorder à la distinction entre..." (Derrida 1972, 55) "Mettre à l'épreuve" as "putting to the test" involves measuring the strength and shortcomings of particular quasitranscendental privilege, suggesting the best theory we can. Yet "épreuve" seems to resonate deeper than a test; it is a challenge, something that one must take up. The further movement is thus one of putting to work the quasi-transcendental in the identification of a distinction: the quasi-transcendental arises out of a context, and is not simply limited by it. By enacting this quasi-transcendental privilege, Derrida is able to make an intervention on religion, a move that, as we will come to see, is 'among, before and after'. 


\subsection{Quasi-Transcendental: Among, Before, After}

Sina Kramer has recently written on this very issue of quasi-transcendental, turning to its first appearance in Derrida's Glas (1968). Kramer nicely summarizes a certain trajectory in Derrida's notoriously challenging text:

To think through the relation between the empirical and the transcendental, Derrida relies on Hegel's "transcendental" sister - the figure of Antigone - as well as Hegel's "empirical" sisters: Nanette Endel (a young boarder in Hegel's family home) and Christiane Hegel (Hegel's own sister). In Derrida's reading, this relationship produces a strange figure, neither entirely empirical nor entirely transcendental, neither both nor neither, a monstrous figure (...) (Kramer 2014, 522)

What is at stake here, similarly as in Faith and Knowledge, is the relation between excess and containment; the 'excess' of the many sisters in Hegel's life, their different aspects, and how they are contained in a problematic 'transcendental' account of the sister in Antigone. This logic of containment - making something fit into the text, containing excess - leads Kramer to characterize the quasi-transcendental through a retroactive temporality. Kramer's point is that the quasi-transcendental always involves a rearrangement of the past considering previous sites of differentiation, and thus gaining its retroactive character. This is what would be at work when, for instance, Derrida draws on inherited, historical concepts of religion to put forth his analysis. Here, we can see one of the three facets of the quasi-transcendental at work in Faith and Knowledge: the 'after' is at work insofar as Derrida's studies deal with traces of the past.

Whether we are dealing with the problem of citation or the relationship between belief and the sacred, Derrida is in each case operating within a certain context of interpretation constituted by historical objects. It is by studying these things that Derrida is able to identify effects of the logic he is interested in. For instance, Faith and Knowledge is in large part characterized by a distinctly historical and etymological study of the term "religion", which allows Derrida to point to a number of places in which concepts are marked by the containment of alterity. Thus, the past offers Derrida the semantic resources necessary to bring about the kind of reconfiguration in which he is interested, which focuses on bringing to light a certain alterity at work against repetition.

Kramer shows great sensitivity to this historical aspect of the quasi-transcendental, 
which, as we have noted, could be understood as the "after" of Derrida's characterization of the quasi-transcendental in Faith and Knowledge. Kramer writes:

Finally, the interrelation of these implications indicates an historical—or perhaps genealogical — method. The retroactive character of the economy indicated by this analysis of the quasi-transcendental orients us to the past in order to unearth the multiple exclusions that are sedimented in our political present. This gives the past to us as a kind of interminable task of translation and interpretation - a task to discover who we are, while taking seriously the limits to such knowledge, as well as a task to do justice to those upon whom we rely, but who we cannot, by virtue of how we are constituted, see, hear, understand, or recognize. (Kramer 2014, 549)

The retroactive temporality mentioned here is at work insofar as the unfolding of the deconstructive logic entails both a turn back to and a reconfiguration of past sites of differentiation. In other terms, Derrida looks at how a difference (ie. Belief/Sacred) has maintained itself in the past, and offers a new characterization of it, where one term comes to stand for the containment of a structural alterity. In this sense, Derrida's turn to the past actively reconfigures it: his operation thus occurs not only after but also before a new context brought about by Derrida's move. Let us further consider how we can reconcile Derrida's threefold characterization, 'among, before, after' with Kramer's claims.

One way to understand this threefold structure of the quasi-transcendental has to do with the self-reflexivity of genealogical claims like the ones in which Kramer is interested. Indeed, while Kramer insists on the importance of a situated quasi-transcendental knowledge, which is to say one that recognizes its limits, this very move comes out in a stronger sense in Derrida's characterization of the quasi-transcendental in Faith and Knowledge. If Kramer mainly focuses on the quasi-transcendental as 'after' the fact, we should here recall Derrida's use of 'among' and 'before' to see how they help with the problem of situation. What is at stake is to characterize the genealogical decision - the turn towards a certain part or facet of the past - as one both involved within a context and opening up this context anew. In this sense, Derrida's genealogical method is not purely genealogical, which is to say that it never leaves historical objects quite intact.

We should also remark upon the specificity of the text considered by Kramer. Glas is an active involvement with writing and form, written in two columns and split into multitudes of smaller non-centered text blocks. The movements of 'among' and 'before' come out particularly 
strongly in Derrida's distortive manipulation of writing. The quasi-transcendental here is one that is among, insofar as it is submerged in Derrida's reading of Hegel. The text cites multiple page passages directly from Hegel, and contains a number of specific and underdeveloped references to his work. Glas operates in this largely inaccessible world, and sets up its logic within it, which is to say, among a set of things or concepts in relation to each other. Finally, the bends and twists of Derrida's texts, leaving nothing intact, calling forth all sorts of new mishearings (such as Derrida's play on the French pronunciation of 'Hegel' as 'Aigle') announce the importance of the 'before' in the quasi-transcendental. The distortion of the text opens up a new set of interpretive horizons. There, Derrida explicitly enacts the impurity of writing which we have seen at work in the first chapter, an impurity which entails that each repetition alters its semantic context. Glas conveys writing as an act of contamination that acts as a 'before' by opening a new way of reading the text.

The kind of philosophical subversion in which Glas functions - quickly picked up on by critics as a distortion of the discipline - entails that it need not insist as much upon the situationality of its intervention. It is a book that, as a reader will notice at first glance, is doing something in relation to a context it operates among (i.e. not philosophy), and calls for a certain reconfiguration, which is to say that it appears before an attempt to engage, a dismissal etc. While Glas is able to perform these aspects of the quasi-transcendental through its form, it is interesting to note that Derrida, in other contexts, is quite explicit about both working within a context and attempting to displace it. In other terms, Derrida seems to have some awareness of whether or not the interventionality of a text shows itself, and when he needs to make it clearer. To varying degrees, Derrida's interventions - particularly in transcribed lectures - give extended acknowledgment to the context of their iteration. This leads to the explicit formulation from Faith and Knowledge that we have repeatedly considered: "among them, before or after them, we will put to the test the quasi-transcendental privilege" (Derrida 2000, 72). One might wonder if Derrida here conceives of academic contexts as characterized by a need to continually reaffirm the possibility of impact or displacement ${ }^{3}$.

The point to make on Derrida's discussion in Faith and Knowledge is that his quasitranscendental interventions can be understood in three relations to a context: among, before and

\footnotetext{
${ }^{3}$ This view would be in line with Derrida's arguments in L'Université Sans Condition.
} 
after. This contributes to Kramer's project, which attempts to think through the problem of constitutive exclusion by using the quasi-transcendental's exploration of the past as a set of differentiations and exclusions. What appears here is that the situationality of such a study need not be added to Derrida's logic as an external feature: it is already apparent within it, in some arrangement of its form and content. Whether Derrida explicitly writes it or plays with the text to make this point, any identification of differentiation or exclusion itself constitutes an intervention - or further exclusion - through a displacing repetition. The rather straightforward point to make, then, is that the quasi-transcendental points to the way in which Derrida's theories or a 'deconstructive logic' are both iterated. They both draw on an existing context of interpretation and change this very context through a displacing repetition.

Thus, we could understand 'Derrida's logic', which we have seen in the preceding section, as a concept repeatable in many different configurations. Here, it is interesting to relate this move to Derrida's typology: in each case, what is at stake is not an overarching logic but a study of its different instantiations. Each repetition would play a role in the constitution of the logic itself, by disseminating its meaning. This re-inscriptability of a 'deconstructive logic' does not entail that is a useless concept. Rather, the possibility for 'Derrida's logic' to be questioned or understood in relation to new contexts is the very reason why it is a useful tool to identify movements in the text.

In the second part of this thesis, we will suggest an interpretation of the works we are considering here that unites them through the expression of a common logic expressed on different terms. Working from our remarks in the first chapter, we will argue that such a logic does not entail a closed space of possibility, but rather expands itself as it is applied to new instances. To this end, we will try to give expression to the movement between Signature Event Context, Faith and Knowledge and Of Hospitality by using Derrida's formulation of a "typology of the forms of iteration". What will be at stake will be showing how, in each text, the general logic of 'iterability' develops new features peculiar to each context, which is to say, each time the problem of 'repetition', the 'proper' or 'the name' arises. 
Chapter 3

Hospitality as a Form of Iteration 


\section{Hospitality as a Form of Iteration}

Of Hospitality is often understood on its own terms, as one of Derrida's important contributions to ethical thought. From this perspective, one might then become interested in the various etymologies taken up in the text, or Derrida's insightful readings of Plato. Yet from the standpoint of a more general deconstructive logic, Of Hospitality shows itself somewhat differently. In this discussion, we will point to the recurrence of a certain logic already taken up by Derrida thirty years prior, in Signature Event Context, and one that we will continue to see at work in Faith and Knowledge. As we have seen, however, Derrida's arguments concerning language entail that we cannot ask where the 'original' logic lies, and which other instances constitute a mere repetition. Indeed, the theoretical reconfiguration at work in Signature Event Concept entails the unification of citational utterance (the idea of an 'ineffective repetition') and the performative (the 'invention' of a new logic) under the category of iterability. The point would then be, as we saw in chapter 1, to set up a typology of the forms of iterations, which is to say a study of the different configurations of iteration and their effects.

We will attempt to build on this move to consider the question of hospitality as a form of iteration. To this end, the first section of this chapter will make the argument that the structure of iterability is in some sense still at work in the question of hospitality. In the second section, we will argue that we cannot deduce the later events of deconstruction from an initial, earlier logic. Rather, as a typology of iterability, each of Derrida's studies on the general problem of iterability entails the expansion of the general concept. In the third part of the chapter, we will argue that this facet of Derrida's work should be kept in mind when transposing specific forms of iterations (i.e. particular events of deconstruction) into new contexts. In other terms, the fact that iterability is an expansive logic entails that it is not limited to a certain lexical field, but should rather be developed to consider the specificities of new contexts, as expressed by the idea of a typology. Building on Shannon Hoff's work on deconstruction and politics, we will consider reasons for which any future deconstruction should critically examine its relation to Derrida's later ethical language. Ultimately, our reading will seek to introduce a new line of questioning in the coming chapters: what characterizes hospitality as a form of iteration? 


\section{$\underline{3.1 \text { Of Hospitality }}$}

Of Hospitality is, like many of Derrida's texts, firstly a performed lecture (or in this case, series of lectures). It is also, as we will seek to show in this chapter, another type of performance: a displacing repetition of a certain logic of repetition-alterity that we have seen at work in Derrida's early writing. We will begin from this problem in order to bring out the wider question of hospitality:

The law of absolute hospitality commands a break with hospitality by right, with law or justice as rights. Just hospitality breaks with hospitality by right; not that it condemns or is opposed to it, and it can on the contrary set and maintain it in a perpetual progressive movement; but it is as strangely heterogeneous to it as justice is heterogeneous to the law to which it is yet so close, from which in truth it is indissociable. (Derrida and Dufourmantelle 2000, 25)

The first distinction - between an absolute hospitality, and a hospitality of/by right [hospitalité de droit - plays an important role in Derrida's analysis. As in Faith and Knowledge, Derrida takes up a detailed etymological study to argue that hospitality is shaped by two distinct moments: just hospitability, as an unconditional welcome, and conversely, the hospitality of right as the necessity to posit a set of conditions in order to actualize this hospitality. We should notice the recurrence of a certain duality which we have already seen in the question of writing: the two drives of hospitality are irresolvable in the same way that repetition is both exposed and opposed to alterity. The question we might ask, then, is the following: why must the opening of hospitality, like repeatability, be characterized by this absolute rupture? Why must hospitality be both open and closed, indeterminate and determinate?

We should clarify, right away, that it is not so much the case that hospitality must be open and closed. Derrida's point is rather that, as a cultural artifact or practice passed on through history, the question of hospitality is shaped by these movements of the question of reinterpretation. The historicity of hospitality is emphasized in several points in the text as Derrida explicitly evokes "the general concept of hospitality". It is likely, given Derrida's extensive work on language, that he is here already thinking of the 'concept' as a historically mediated. In simple terms, the meaningful experience of hospitality as an imperative should not occlude the way in which Derrida's account ties meaning to repeatable, historical concepts.

We can further explore this question of necessity by relating this text to earlier works. In 
Margins of Philosophy, Derrida speaks of spacing (espacement) as "the becoming-time of space and the becoming-space of time". In Of Hospitality, Derrida speaks of hospitality as "the becoming-law of justice" (Derrida and Dufourmantelle 2000, 73). The recurrence of this formulation is by no means random: what we see in both moments is a productive irresolvability. In the early Derrida, the point is that difference must be spatialized across time. In other terms, no difference can become itself if it is not spatially marked across time, and there are, conversely, no "moments" without an ongoing spatial differentiation. We see a similar relation at work in the question of hospitality: absolute hospitality can only be actualized in conditions, but these conditions are only meaningful based on their ability to persist across different contexts. The becoming- $x$ of $y$ relation used by Derrida points to a relation of co-implication and coconstitution that runs across his work.

We can relate this to the idea put forward in Derrida's work on iterability: the use of determinate signs is made possible by the absolute contingency of repetition. Repetition and alterity condition each other. There, we saw that a certain split between a sign and its possible contexts - the capacity to apply a sign to a wholly different context - was both the chance for meaning and misunderstanding. In other words, our ability to freely repeat a word allows us to make sense of new situations. In this context, we saw Derrida make the argument that this repeatability must be absolutely contingent. Let us turn back to the early Derrida, from which we will attempt to extract an important point:

My "written communication" must, if you will, remain legible despite the absolute disappearance of every determined addressee in general for it to function as writing, that is, for it to be legible. It must be repeatable - iterable - in the absolute absence of the addressee or of the empirically determinable set of addressees. (Derrida 1982, 315)

Much like just hospitality, writing must remain in some way radically open, and must in some important sense relinquish control over what is to come. Here, it is helpful to look at why this openness must constitute a radical, heterogeneous break in the question of writing. Derrida's point is that a sign must be re-inscribable in a new context. Thus, a word like "difference", printed on a page, can be taken up in a number of contexts: by Derrida, within a text, by us, today, by someone else, in the future. What makes "difference" a meaningful word is precisely its ability to be taken up in new ways: Derrida's point is that this break is a condition of meaning. A concept tied to a particular context would not be repeatable, and thus, would could not be used 
as a means of sense-making in new contexts. In short, the problem here is that we cannot refer to something that is not repeatable in a manner absolutely distinct from its original context.

The question of hospitality offers another good way to think about this problem. If the break of hospitality was only partial, which is to say, if hospitality could be reduced to a minimal set of conditions, its movement would be limited to a specific context in which such claims would be meaningful. In other terms, the reduction of hospitality to a set of conditional terms precludes its becoming and hinders its ability to be reaffirmed in different contexts. This follows from the claim that such conditional claims are formulated in a language specific to a context (i.e. 'hospitality as welcoming humans'), but that such conditional terms cannot grasp forthcoming contexts, as for instance one in which hospitality would extend beyond the human. The heterogeneous open-endedness of hospitality allows for the renewal of such conditions: it allows for hospitality to become itself anew in every context, paying attention to the contextual reconfigurations of meaning. Hospitality has to be able to do this, since configurations of meaning change: a particular 'hospitable' behavior is defined in relation to its context. The openendedness of hospitality thus shows the way in which a historically mediated practice of 'hospitality' has dealt with the possibility of its re-inscription.

We can thus make the same point previously explored in relation to Faith and Knowledge: there is, in some minimal sense, the continuity of a movement or logic from Derrida's early work on language to his later writings on ethical questions. This recurrence can be characterized in several ways, as for instance an irresolvable opposition between repetition and alterity. On the other hand, as we have seen, the terms of Derrida's late work are quite different. The contingency previously characterized by repeatability now takes the form of justice, or an ideal of absolute hospitality. Thus, we should notice that while iterability is at work here in some sense, we cannot simply subsume the logic of hospitality within questions of language. The same problem Derrida is interested in will come to bear different effects across these two contexts. Here, we should turn back to Derrida's typology of the forms of iteration. Indeed, is it not this very problem - a shared logic that generates different effects - that leads to project of a typology? This move is particularly useful for our project here: the comparison of different scenes united by a certain logic, but a logic each time widened by the introduction of a new situation. Thus, what is at stake is two-fold: to observe what characterizes the form of iteration at 
work in the question of hospitality, and to consider how this form expands the initial conception of iteration put forth in Signature Event Context. 


\subsection{Enriching the Logic}

Seen through the lens of iterability, Derrida's localized rewritings of a recurrent logic insist upon the importance of context. Let us recall our discussion of a typology of iterability. What is at stake is to observe various instances of iterability - of the relation between repetition and alterity - and how they unfold, instead of reducing them to one fixed logic. We have insisted, in this context, that Derrida's commitment to the open-endedness of concepts and to the alterity inherent to repetition entailed that there could be no final logic of iterability, and that the concept was itself disseminated. Thus, the study of different configurations of iterability should replace the search for an all-encompassing predictive principle. Here, we will consider how $O f$ Hospitality acts, in some sense, as a further study of iterability, and as such that it should be taken as a type, and not as a master logic of deconstruction. The point to make is then that Derrida's concept does not outline a limited set of possibilities; it is rather expanded by the specific effects that arise every time it is used in a new context.

A result of this move - the localized instantiation of Derrida's logic - is that the logic itself comes to be conditioned by the context in which it appears. Consider the following brief passage from Of Hospitality:

(...) Absolute hospitality requires that I open up my home and that I give not only to the foreigner (provided with a family name, with the social status of being a foreigner, etc.), but to the absolute, unknown, anonymous other, and that I give place to them, that I let them come, that I let them arrive (Derrida 2000, 25)

As we have seen, Derrida is in some sense reiterating the sort of radical repetition/alterity split proper to his account of recontextualizability. In other terms, for something to have meaning over time is for it to face an absolutely open-ended possibility which cannot be contained in conditional terms. We saw that in the context of repeatability, where a sign would only be repeatable if it could be entirely separated from its original context, and thus absolutely exposed to the possibility of continuity or extinction. Here, the point is very much the same: the openended aspect of hospitality puts the conditional determination entirely at stake, allowing a conditional action to have meaning as hospitable across different contexts. Open-ended hospitality allows us to redefine hospitality in an entirely new set of conditional, contextual terms. 
We should pay closer attention to how this remainder - the possibility for re- inscription, change or becoming - manifests itself. In the context of language, alterity manifests itself alongside repetition, as the motor of repetition and the condition of meaning. In the question of hospitality, however, this movement of repetition and alterity manifests itself differently: here, contingency is not merely a feature of our use of language but expressed through an ethical imperative. The meaning of alterity is disseminated through Derrida's words, as he speaks of the "absolute, unknown, anonymous other" and a giving place to this other. What we see here is that to spell out a certain deconstructive logic on the terms of hospitality is to observe a new set of effects, such as an ethical imperative. While the questions of communication and hospitality are both characterized by the possibility of repetition, we see here that to limit them to one theoretical framework - i.e. iteration as seen in Signature Event Context - would be to disregard a set of effects proper to ethical questions such as that of hospitality. In fact, this problem is quite similar to the one encountered in chapter one: to claim that both citational utterances and performative speech acts are iterated is not to do away with their differences and flatten them to one unique process of iteration. It is, rather, to see how the problem of iteration plays out in different contexts, and what particular effects arise in these new contexts. This move is particularly useful here, as it steers us away from questions of whether Derrida introduces a "new" logic or merely "repeats" the old one without any further effects. The point is rather to see how later instantiations of Derrida's logic bring about new effects, and how hospitality operates as a form of iteration.

As we have seen, the co-implication or irresolvability of both facets of hospitality functions in the same manner as the opposition of repetition and alterity in iterability: neither one can be sustained without the other. Despite this, we should observe the way in which this opposition manifests itself in the context of hospitality, where indeterminacy appears in the form of a certain ethical imperative. By the same token, we can begin to observe just how important a role context plays in the unfolding of Derrida's arguments. At a basic level, we are talking about similar things in Signature Event Context and Of Hospitality: iteration as the co-implication of repetition and alterity. This is precisely why, when we iterate conditions of hospitality, we must deal with the possibility of their re-inscription conveyed in the ideal of an absolute hospitality. In both cases, we see that a certain alterity, as the possibility for repetition, is the condition of repeatable and meaningful concepts. The important departure in Of Hospitality, however, is that 
this alterity brings about a new set of effects. What appears to be a mere structural feature of language manifests itself as an ethical imperative in the context of hospitality. Finally, the point to make is that this expansion of the logic of iterability does not follow from its initial appearance in Signature Event Context. The affective or ethical side of hospitality as a form of iteration is not deduced from its definition, but rather arises when the problem of iterability is identified in these specific contexts. 


\subsection{On the Transposition of a Deconstructive Logic}

In "Translating Principle into Practice: On Derrida and the Terms of Feminism" (2015), Shannon Hoff makes two claims. First, she argues that Derrida's Of Hospitality makes a point about the dependence of conditional statements on unconditional norms. Second, Hoff suggests that this serves as a useful political insight, focusing on the question of feminism and inclusivity. Hoff writes:

In his analyses of justice, forgiveness, hospitality, democracy, and the gift, Derrida highlights a necessary tension between the unconditional norm and the conditioned realization that is constitutive of each of these realities; it is my intention to demonstrate a similar tension within feminism and to argue that this tension is intrinsic to the exercise of feminist responsibility. (Hoff 2015, 404; emphasis added)

In the context of our analysis, what is at stake is clarifying the status of the necessity to which Hoff alludes, and its relation to both the question of iteration and the politics of deconstruction. Is this tension necessary insofar as it is a general explanatory principle? As we have seen, attempting to push any deconstructive infrastructure to this level of necessity raises a number of challenges. To make this point, we might simply restate a problem evoked earlier: any such necessity, to be made sense of, must be iterated, and this iteration - if we follow Derrida - would seem to get in the way of a proper necessity (insofar as it contains a residual contingency proper to repeatability and meaning). In this sense, as we have seen, Derrida's logic comes to condition its own claims.

We should pay special attention to how this movement plays out in Hoff's intervention. Hoff suggests:

In his treatment of hospitality Derrida shows that, no matter where we begin, our consideration will lead us to these two conflicting points - toward the idea of an unconditional, absolute openness and toward the specific, conditioned way in which the capacity for openness is preserved. (Hoff 2015, 405 first emphasis added)

Here, Hoff's use of "no matter where we begin" captures a certain ambiguity at work in Derrida's logic. On the one hand, there is a certain sense of necessity at work in the movement of irresolvable oppositions identified by deconstruction. In other terms, as Hoff rightly points out, just hospitality cannot function without hospitality of right, and vice versa. This irresolvability seems to be a general feature of Derrida's logic and shows itself in a new way in the context of 
hospitality.

Yet there is another sense in which the deconstructive logic identified in Of Hospitality does not operate regardless of where we are, since the iterability of writing does not permit this kind of cross-contextual relevance. In fact, where we begin seems to matter a lot for Derrida, whether in Capri, for Faith and Knowledge, in Cerisy, for Rogues, or even in Europe, for The Other Heading, contexts which he acknowledges in detail. Each time, Derrida, settles into his new thematic surroundings before any theoretical operation, and carefully spells out this site. Where we begin - the place, the language passed onto us, the practices, the repeatable processes of reasoning - all of these factors shape how the traces of a certain logic of repetition-alterity might come to show itself. As we have seen, Derrida's intervention thus takes place 'among, before and after' a specific context. In other terms, to pick up on the effects of a general deconstructive logic in a particular context (as that of hospitality) demands learning to speak that language, and spelling out the deconstructive problem on its terms. This is another way of saying that the possibility of repetition or re-inscription is never quite the same since it is each time iterated in a new context. In language, such a possibility manifests itself in the repeatability of a word: in hospitality, in the conception of hospitality as a just and unconditional welcoming.

Hoff seems to identify a variation on the problem of iterability, as she suggests that "determinate actions undertaken on behalf of the ideal of inclusion can be criticizable in the terms of the very ideal that inspires them.” (Hoff 2015, 407) The question of iterability is at work here insofar as the relation between determinate actions and the ideal inspiring them is mirrored onto the problem of repetition and alterity. Alterity is both the possibility of repetition and the exposure of repetition to change. In language, repeatability allows us to repeat words in useful ways, but entails that these words are in turn not bound to a specific context and thus reinterpretable. Similarly, the ideal of hospitality allows us to formulate concrete hospitable actions, but in turn allows for such actions to be reexamined. This feature of hospitality, on Hoff's reading, bears important political consequences:

Such challenges are intrinsic to such forms of political struggle. Therefore they require a commitment, first, to be aware that any specific means of enacting justice could be onesided; second, to engage with that which might challenge that one-sidedness; and third, to be willing to risk our commitments." (Hoff 2015, 407) 
Here, we should clarify the type of requirement or normative demand at work in Derrida's text. Insofar as deconstruction is iterated on the terms of a changing context, which is to say, finite, any normative demand cannot arise out of a fixed principle. In other terms, the necessity at work in Derrida's interventions operates in specific contexts spelled out in his work. It is thus a local necessity, which arises in the context of hospitality, on its term, and in the context of feminism, on the terms spelled out by Hoff. Thus, the transposition of a deconstructive logic onto a new context is not merely its repetition: it is, rather, its dissemination through the introduction of a new form of iteration. The necessity is not derived from a general principle; rather, the general principle allows us to observe particular sites of irresolvability spelled out in different terms.

We can begin to see the importance, at a political level, of justifying the theoretical status of deconstruction. In short, the claim that there is undecidability, or that there are concrete structures of irresolvability at play, can only reach the degree of stability granted by specific changing contexts, which is to say, never quite enough for a transcendental condition of possibility. Further, Hoff suggests "What I see to be helpful here, however, is the identification of the principle behind such transformation." (Hoff 2015, 408) Again, what must be insisted upon here is that the principles identified by Derrida are finite and strategically used within specific contexts. This makes their transposition across different contexts, or the possibility of their translation, a concern. The further point is that a politics of deconstruction is structurally incapable of providing any definitive structures or conditions, but rather acts a local level by studying particular historical concepts, practices and objects.

In the context of hospitality, the effects of indeterminacy or alterity are equated to a certain imperative or ethical demand to unconditionally welcome the other. This same structural feature - the manifestation of alterity as an ethical demand - seems to shape Hoff's transposition of deconstruction: "Feminism risks the very values that urged it into being in the first place if it makes retention of its own specific identity its ultimate goal." (Hoff 2015, 409) Here, the exposition to alterity appears as more than a mere structural feature of meaning that in turn concerns political action. In other terms, this is not simply the linguistic claim that the term "feminism" is exposed to the contingency of repeatability. Rather, Hoff's claim seems closer to the account of contingency seen in Of Hospitality: alterity is associated with a certain demand or ethical imperative to welcome what is other to oneself. 
The point of understanding "hospitality" as a form of iteration is thus twofold. First, it grounds the movement of repetition and alterity in a particular context; second, it depicts this manifestation of iteration as merely one amongst many. Repeatability, for instance, does not come about in the form of an ethical imperative - or certainly not as much as the late formulations of justice and unconditional welcoming. It simply bears a certain possibility of reinterpretation and re-inscription that Derrida is interested in. The point to make is that when applying a deconstructive logic to new contexts, as Hoff does, one must firstly ask: what form does the logic of iteration take in this particular context? How has a concept been shaped by the possibility of its inter-contextual re-inscription?

In the later events of deconstruction, Derrida seems to have a certain interest in a particular set of these effects of contingency, characterized by lexical and affective fields related to the ethical, religious, and political. Along the way, he begins to characterize these effects with a new set of terms peculiar to the context in which he is working: the contingency of repeatability becomes the impossible, absolute hospitality, or the call of justice. The point to make, however, is that these are not final descriptions of the logic or question Derrida is after. The structure of iterability does not permit such a final account. They are, rather, localized effects of a certain irresolvability that Derrida begins to explore in his early work on language: forms of iteration. The later accounts of alterity in Derrida's work are then not meant to be totalizing. The deconstructive logic entails that it can show itself in a number of ways: thus, when applying deconstructive insights to a new context, one is not limited to the terms of a particular deconstruction.

This is important to note since, when working within new, specific contexts, one should question the accuracy and usefulness of a certain set of semantic resources to express the movement of deconstruction. For instance, what function does the sign "justice" or "unconditional norm" play across different configurations of meaning? It is here that the early work on language is particularly helpful from a political perspective. The dissemination of meaning entails that we should pay attention to the ongoing reconfigurations of meaning. For instance, one might consider semantic reappropriations of a term such as 'justice' at odds with openness or unconditionality. The point is, of course, not to claim that we should each time "invent" a new deconstructive logic, since Derrida has very clearly argued against such a 
conception of language or theory. The point is rather that deconstruction entails the corruption of its own logic by setting it up anew within every new context. This is particularly evident in a work like Faith and Knowledge that both uses a number of recurrent Derridean tropes, such as iterability, and extends their scope by introducing new effects of the repetition-alterity relation. 


\section{$\underline{3.5 \text { A Matter of Context }}$}

In the lectures on hospitality, Derrida immerses himself into the language of hospitality to explore the terms on which a certain form of iteration, which is to say of the relation of repetition and alterity, has manifested itself. Yet Derrida does not invent terms like "just hospitality" or "hospitality of right"; they are extracted from his readings of Benveniste and others. The point to make is that Derrida builds his logic anew using the parts around him, paying particular attention to the context in which he is operating. In the context of hospitality, iterability manifests itself as the opposition of a hospitality of right to a just hospitality. The specificity of such contexts in relation to deconstruction suggests that the political problem here does not have to be formulated, as in Hoff's essay, within the framework of ethical terms. For one, the structure of the unconditional/indeterminate does not have to be something that is contemplated, as one looks up to an ideal. It manifests itself, in other contexts, as the site of a constitutive contingency at work in the repetition of any determination. To be sure, there might be something praiseworthy about the type of unconditional hospitality that Derrida speaks of in Of Hospitality. But Derrida's point is that hospitality as a practice and concept bears a trace of a residual contingency, of a certain room left for becoming. This contingency appears in the trace of a just hospitality, but does not have to be reduced to it as ideal: such an ideal hospitality is merely an effect, or a mechanism allowing hospitality to subsist across different contexts. Here, we see the way in which Derrida's interventions both refer to a wider logic and are inscribed anew in different contexts. What is happening in hospitality is not simply the logic of iterability, but neither can the logic identified in hospitality be limited to its specific context. Hospitality is both marked by, and contributes to, Derrida's project, as a specific form of iteration.

As a type of iteration, the logic of hospitality cannot contain every instance of iteration in other contexts. In other terms, the logic of hospitality is not an account that allows us to uncover conditions of possibility applicable to any context. Rather, the deconstructive move investigates localized sites of possibility: for instance, the possibility of hospitality in becoming arises in the account of just hospitality. To extract this condition of possibility from its context is, however, a different move, since it is not the case that there is a logic according to which conditional statements are regulated by unconditional ideals. Rather, certain singular contexts reveal a set of dynamics that can be subsumed under this movement. The identification of such a dynamic is 
strategic: it is determined after the fact, and does not constitute a purely explanatory model. Derrida does not impose his framework on hospitality, but lets hospitality spell out its own constitutive tension, on its own terms. Thus, the relation between conditional claims and an unconditional ideal is not a general feature of experience, history, or culture. It is rather a specific, localized effect of a certain phenomenon or logic that Derrida is interested in. In this sense, one cannot simply transpose a deconstructive logic from one text to another, but must actively consider how such a logic relates to a specific context.

Certain features of the lexical field of hospitality, we would argue, play in to Hoff's reading of the text. This semantic configuration discloses the possibility of repetition alongside ethical and affective experiences. Our argument entails that this is merely one effect or configuration of the deconstructive logic, which is to say that alterity does not have to be framed in the terms of an ideal. This may be a useful move in Derrida's seminars insofar as it shows that the historical genesis of hospitality as a set of concept and practices has had to deal with this excess or contingency. In other terms, when Derrida speaks of an ideal, he is speaking the language of hospitality, and in turn telling us something new about the relation between repetition and alterity (i.e. that it can show itself through an ethical imperative). The language of hospitality - Derrida's language of hospitality - is not necessarily the language of politics, which is to say that we should be particularly mindful of context. In fact, Derrida's excursions into many different contexts should, by itself, make this point: becoming manifests itself slightly differently in every context, in every new language, or in every new material configuration. Yet from the standpoint of a typology, it is also coherent to see how we might reuse previous forms of iteration identified by Derrida. In this sense, we could read Hoff's argument as the suggestion that the form of iteration conveyed by hospitality is also at work in the political question, insofar as these instances of iteration are characterized the containment of alterity in the form of justice or an ethical imperative. The point to make, as we have noted, is that this form is inherently linked to the context in which it arises. 


\section{Chapter 4:}

Ethical Iteration and the Politics of Deconstruction 


\section{Ethical Iteration and the Politics of Deconstruction}

In the previous chapter, we suggested that the terms and operations of Derrida's deconstructions should be understood in relation to their contexts. We argued that different contexts focused on different effects of a similar logic at work across several of Derrida's texts. There, we made the point that the reiteration of deconstructive logics should strategically consider its use of terms in ways that could possibly go against Derrida's own usage. In this chapter, we wish to outline one impact of Derrida's turn to new contexts. It concerns, again, the relation between a deconstructive logic and its context - which is to say, the set of effects constituting a recurring logic. Here, we will further develop Derrida's account of religion to suggest a new form of iteration characterized by a certain politicization of alterity.

To make this point, we will consider Kearney's interpretations of Faith and Knowledge (1991) and Of Hospitality, which raise a similar criticism: a preference for alterity in Derrida's arguments. The general point we will attempt to make is twofold: first, Derrida's 'logic' does not prioritize alterity, but rather seeks to show its co-implication with repetition. In this sense, what Derrida is concerned here is still, in some form, the question of iteration. Second, Kearney's response to Derrida is a function of the particular form of iteration proper to the context of religion. The ethically and politically loaded language Derrida uses in his later works - justice, the wholly other [tout autre] or just hospitality - carries a normative weight that feeds a certain imbalance between determinacy and indeterminacy. This imbalance will come to characterize the particular form of iteration at play in the question of religion. The final point is that this form of iteration should be thought alongside a certain political question at work in Derrida's thought. 


\subsection{Kearney and Hospitality}

In "Strangers and Others: From Deconstruction to Hermeneutics", Richard Kearney responds to Derrida's account of hospitality. Kearney's general argument is that Derrida favors openness or indeterminacy, but that such an indeterminacy should be thought alongside a hermeneutic of suspicion. In other terms, while we should be open to the radically other, Kearney argues, such an opening must be thought alongside a certain discernment of alterity. The same general critique, as we will come to see, is brought up in response to Derrida's work on religion. Despite attempting to draw distinctions, Kearney's positions in these critiques end up remaining very close to Derrida's: a recognition of alterity as co-implicated with determination. Our aim here will be to clarify their disagreement, granted that there really is one.

Kearney's general argument equates the rupture between repetition and alterity - which we have seen at a number of different levels in Derrida's work - with a certain valuation of alterity. In other terms, Kearney's reading of Derrida seems to either miss (or dismiss) the latter's point that alterity is co-implicated with repetition. Depicting Derrida's view, he writes: "justice demands more: namely, unconditional hospitality to the alien. Hospitality is only truly just, this argument goes, when it resists the temptation to discriminate between good and evil others" (Kearney 2002, 10). We should note the similarities to Hoff's reading. In both cases, the definition of alterity as the "just" seems to play an important part in how it is interpreted: both accounts give space to a certain demand or imperative emanating from alterity, here conveyed as a resistance. On Kearney's reading, Derrida holds up this ideal as the only true and just hospitality, a position that comes out in a much stronger way later in Kearney's discussion:

Derrida affirms the priority of a hospitality of justice - open to the absolute other as another without name. Here we supersede the hospitality of law. What distinguishes the absolute other is that it is without distinction, that is, without name or proper name." (Kearney 2002, 11)

We should clarify the movement of superseding alluded to by Kearney. Here, Kearney is working from a quotation where Derrida elaborates a certain conception of hospitality as unconditional or just: "The newcomer may be good or evil, but if you exclude the possibility that the newcomer is coming to destroy your house, if you want to control this and exclude this terrible possibility in advance, there is no hospitality." (Derrida 1999, 66) Derrida is here arguing that hospitality reaches beyond its expression in conditional terms, or that the possibility of 
hospitality extends beyond specific contexts. This reaching beyond, however - the sense in which unconditionality supersedes conditional hospitality - does not do away with the latter. As we have seen in other moments of Derrida's work, such as the metonymy of the ellipse and the recurrence of the becoming- $x$ of $y$ form, what is at stake is a relation of co-implication: just hospitality exceeds the hospitality of right, but can only be actualized through it. Here, it is useful to turn back to the question of language: the repeatability of a word - the fact that it can be applied to an incalculable number of contexts - does not prevent us from using words, and is not opened up without the determinate use of words. In simple terms, there is no alterity or problem of interpretation if we fully give up on language and repetition, but this is not what Derrida is up to here. He is rather trying to think through the entanglement - which is to say, the irresolvability - of repetition and alterity. 


\subsubsection{Clarifying the Disagreement}

Putting forth his own suggestions towards the end of the essay, Kearney writes:

By refusing to treat the other as so exterior or unconscious that it becomes the utterly alien self, hermeneutics not only alters the ego into oneself-as-another but guarantees that the other, for its part, retains a certain fluidity and equivocity. The other is neither too close nor too far, neither too familiar nor too foreign, to escape my attention. (...) Indeed I would argue that it is because of this ethical contact, always striving to make the other that little less alliance, that can tender (however provisionally) different interpretations of this or that other. (Kearney 2002, 29)

What seems to be at play here is a certain determinative flux: an other that we know, but which in other senses have still yet to know - a provisional discernment. There are two ways to read this move in relation to Derrida's project: Kearney could be arguing against a version of deconstruction in which the other is only wholly other, completely void of determination, or he could be arguing that deconstruction gives too much room to indeterminacy. The first option is, from a theoretical standpoint, not very convincing. Here, our consideration of Derrida's earlier work is of help: the relation of repetition and alterity is a relation of co-implication. Thus, Kearney's suggestion - that otherness has to be co-implicated with determination, with making sense - is in fact the very movement alluded to by Derrida's logic.

Whether intended by Kearney or not, the other criticism - that Derrida gives too much room to indeterminacy - is a much more striking one. This interpretation localizes Derrida and Kearney's disagreement to a much more precise question on the political use of indeterminacy. In an interview with Kearney, Derrida shows more awareness of this problem. Turning to this exchange between Kearney and Derrida:

Kearney: (...) For me it is a hermeneutic problem: how do you speak, and name and identify a God without falling back to metaphysics and onto-theology and yet without saying "God is khora."

Derrida: I never said that. . . (Kearney 2004)

This exchange concerns Derrida and Kearney's work in relation to religion, but maps on to the problem of hospitality remarkably well. "Khôra", a term we will have the chance to come back to, is a late iteration of alterity in the repetition-alterity relation. Thus, when Kearney equates "God" (as repetition, present) with "Khôra" (as alterity, absence), Derrida is quick to rebut: 
alterity and repetition, on his account, cannot be equated or made one. Without applying a totalizing logic across Derrida's work, we might nonetheless use the recurrence of this structure to clarify these texts. "God" [repetition] is not "khôra" [alterity], in the same way that our use of language is shaped by both the repetition of determinate terms and the open-ended possibility of their interpretation. From this standpoint, equating God (the presence or representation) to khora (absence) is tantamount to the claim that the open-endedness of interpretation makes all communication purely contingent. What we see in the context of language, however, is the opposite movement: alterity does not disable the possibility of meaningful repetition but rather constitutes it, insofar as it represents the capacity for an ongoing adaptation and reconfiguration of changing contexts. Alterity allows us to keep meaningful things across time, but also implies that those things might change. Thus, deconstruction does not do away with representation or appearance but simply inscribes it in a system of repetition opposed to alterity.

Beyond this textual problem, however, what appears to be at stake in the DerridaKearney exchange is the relation between repetition and alterity. These motivations come up more explicitly as the interview unfolds:

Kearney: I know you never said that but you see the problematic . . .

Derrida: (...) The differences between us are so thin, that we cannot in a short discussion do justice to them. These thin and sometimes imperceptible differences or nuances could be translated into politics. But we cannot reduce them to that. (...) I have the responsibility to acknowledge, to obey the necessity of the possibility that there is khora rather than a relationship with the anthropotheologie God of Revelation. At some point, you, Richard, translate your faith into something determinable and then you have to keep the "name" of the resurrection. My own understanding of faith is that there is faith whenever one gives up not only any certainty but also any determined hope. If one says that resurrection is the horizon of one's hope then one knows what one name when one says "resurrection" - faith is not pure faith. It is already knowledge. That's why sometimes, you call me an atheist ... (Kearney 2004)

Derrida's answer is helpful in locating his specific point of disagreement with Kearney. Both conceive of a movement from alterity to determinacy, or a movement of return from the openended other to the self's conception of the other. For Derrida, however, this return from alterity as a repetition (i.e. making sense of something, identifying it through existing words) continues to depend on alterity. We can reformulate this move on the terms of language: what makes words useful is not only the fact that we are able to repeat them, but also that they are repeatable in new 
contexts. Absence - as the possibility of repetition - persists, since we would have little use for a word we could not repeat or apply to new situations. In the context of belief, it implies that we can look back on our different beliefs and reevaluate them in relation to a new context.

This appears very close to Kearney's thought. The same logic seems to ultimately drive the movement to "tender (however provisionally) different interpretations of this or that other" (Kearney 29). The structure of provisionality put forth by Kearney evokes Derrida's coimplication of repetition and alterity and the notion of a 'remainder'. The point to make, then, is that this disagreement is not primarily theoretical or structural. In the coming section, we will make the point that it rather has to do with a certain emphasis on alterity put forth by Derrida, which is proper to this particular form of iteration. 


\subsection{Khôra: Alterity as a Political Resource}

We will now return to Derrida's Faith and Knowledge (1991), which we briefly considered in chapter two. Here, Derrida is going to characterize alterity (in relation to religion) in two important ways: khora, a term which Derrida borrows from Plato's Timaeus, and the 'messianic'. Derrida's reformulation of alterity as khora contains a set of new descriptive terms recurrent in the later ethical works. What will be at stake here is to show how these terms characterize one of the forms of iteration in Derrida's late works. Faith and Knowledge begins to raise a form of iteration characterized by the politicization of alterity. Speaking of khora, Derrida writes:

"It would link pure singularities prior to any social or political determination, prior to all intersubjectivity, prior even to the opposition between the sacred (or the holy) and the profane." (Derrida 2002, 29)

We should note the striking effect of this reformulation of alterity. Here Derrida tells us that indeterminacy provides an originary link prior to determination. What appears to be at stake here is a certain universalism of a constitutive relation between alterity and repetition. We should note the remarkable departure from Derrida's early characterizations of alterity in Signature Event Context. This iteration of alterity defines itself a 'link' preceding historically constructed links. While it has a structurally similar function as alterity, namely, the possibility of re-inscription, this manifestation is decisively different.

While Derrida is dealing with the general problem of iteration - here, the iteration of belief, and the relation to the "proper" - this specific form of the problem shows itself alongside a new set of effects. The appearance of the problem of iteration within a religious context brings about a reconfiguration of alterity not only as a structural feature of language, but as a unifying structural condition of belief. The unfolding of a logic of iterability in the context of religion allows Derrida to bank on a certain effect: iterability as a unifying force beyond determinate beliefs. This form of iteration proper to the context of religion would, on Derrida's account, introduce the possibility for a new political project. We will take up this very problem in the final section. 


\subsection{Alterity as Messianic}

We have made the point that Derrida's intervention within the ethical and religious domains can be read, amongst other things, as the outlining of a new form of iteration. What is at stake, in this specific context of religion, is to observe how the question of naming or determination manifests itself in relation to a certain affective or unifying experience. In this final section, we will suggest that this feature, particularly apparent in Faith and Knowledge can be understood in relation to a certain political strategy put forth by Derrida. To conclude, we will consider why certain forms of iteration might be more promising in view of Derrida's project, but that a politics of deconstruction need not be limited to it. In other terms, what will be at stake will be to point to two moments: the identification of different forms of iteration, and how a politics of deconstruction relates to these different forms.

The other formulation of alterity as messianic, in Faith and Knowledge, further emphasizes the specificity of the religious question as a form of iteration. There, Derrida speaks of:

(...) the messianic, or messianicity without messianism. This would be the opening of the future or to the coming of the other as the advent of justice, but without horizon of expectation and without prophetic prefiguration. The coming of the other can only emerge as a singular event when no anticipation sees it coming, when the other and death - and radical evil — can come as a surprise at any moment. Possibilities that both open and can always interrupt history, or at least the ordinary course of history. (Derrida 2002, 56)

We should, by now, be able to read such passages in relation to the wider question of iterability. Thus, what we are dealing with here is a further iteration of alterity, in which it arises as the messianic, on the terms of this new context. Derrida is unpacking his logic in the context of religion and finding new tools to illustrate the movement taken up in other texts. What we should notice here is the further formulation of new effects: alterity as ethical and characterized by force. Whether or not such effects have appeared, at a minimal level, in other events of deconstruction is not directly concerning. Our point is rather to show how the different contexts in which Derrida is working affect the presentation - and thus meaning - of its logic.

The question of the messianic illustrates this point. Here, Derrida is reconfiguring the movement or force of messianicity without the final term - the apparition of a determinate 
messiah. The emphasis is on a dynamic movement towards an irresolvable alterity. Further, there is an implicit downplaying of determinacy in the reference to a "messianicity without messianicism" (Derrida 56), wherein the second part of the expression refers to determinacy. Here, even more so than in the case of hospitality, a reader would be justified in seeing Derrida as being on the side of alterity.

It will not do to simply suggest that Derrida has changed his logic here. His reply to Kearney in the interview previously quoted should illustrate this rather clearly: Derrida is not turning to the absolutization of indeterminacy. Yet the general turn towards alterity identified by Kearney's criticism, beyond details of the logic, stills bears weight on Derrida's argument. Here, the Kearney-Derrida interview is helpful. Kearney is speaking of khora, and we are reminded of alterity as the condition of repetition which itself exceeds repetition:

Kearney : Which is prior to all differences and yet makes difference possible ...

Derrida: Yes ...

Kearney: And this can lead to a new politics, another kind of cosmopolitanism.

Derrida: Beyond cosmopolitanism, since cosmopolitanism implies a state, a citizen, the cosmos. Khora opens up a universality beyond cosmopolitanism. That's where at some point I am planning to examine the political consequences of the thought of khora which I think are urgent today. (Kearney 2004)

Here, we can begin to tie the new descriptive features of alterity observable in Derrida's late works to a certain political project. The project involves, as Derrida explicitly states here, a new universalism based on a shared conception of alterity. We should however be mindful of how this argument can be made in the context of Derrida's thought. The turn towards alterity as a political resource does not and cannot imply the dissolution of determinacy. It rather seeks to expose indeterminacy as a condition of determinacy, and to develop a politics out of this shared condition or structure.

There are many issues to ask in relation to this project: its feasibility, its structure, and how much influence it bears upon the earlier or later events of deconstruction. The point we wish to make here, however, is much narrower. We cannot think Derrida's late iterations of alterity as the messianic, justice, and so on, as ineffective uses of language to convey a fixed logic. Rather, 
following Derrida's early insights from Signature Event Context, we should here question the languages being spoken, their resonances and influence on the constitution of meaning. Turning back to our earlier discussion, what we see here is a certain form of iteration with a set of effects quite distinct from those in the question of language. Thus, to restate the deconstructive logic on new terms disseminates its meaning, and exposes it to change. Here, such a movement is at work in the emphasis on alterity as a universal ethical demand. What this reflection highlights, however, is two-fold: first, we should question Derrida's relationship to his contexts. One might wonder, in this vein, if he is drawing from the semantic and affective world of religion to convey a new politics of deconstruction. Second, these observations should clarify why deconstruction cannot be limited to a formal framework, and how context comes to emphasize certain aspects of the logic. They emphasize various semantic fields and contexts as both sites of responsibility and strategic tools for the unfolding of deconstruction. 


\section{Conclusion}

Our general argument has been that 'deconstruction' or its logic is disseminated, which is to say that Derrida's own arguments make it impossible to come up with a final logic of 'how things are'. The line of thought we have considered, however, tries to move away from this understanding of iterability as a negative limitation. Rather, we have argued that the different semantic resources available in different situations - which is to say, the different words, practices and things proper to a specific question or historical object - allow, on Derrida's view, for a potent dissemination of a wider logic. To ignore the specificity of such contexts would limit the effect of a certain theory or logic. This is what we saw at work in Signature Event Context: Derrida is not interested in the claim that "everything is iterated" or, in another formulation, "everything is a construct". Rather, the strength of his theory comes through its ability to be applied to new contexts, and thus, as we have argued, to identify new forms of iteration or new textures of construction. The logic of 'construction' is thus ongoing and multiple. The new forms of iteration we have identified represent localized effects of how specific things, such as hospitality or religion, come to persist through different contexts. At the same time, these studies enrich the wider repetition-alterity relation by relating a new set of effects to the overall logic.

The point to make, then, is two-fold. First, Derrida is not interested in providing a general logic that can explain or account for a number of different situations. Rather, his interest lies in disseminating the ideas that appear from early on in his work - iterability, différance - in order to expand their scope and identify new. Second, this puts forth a new understanding of Derrida's work as quasi-transcendental. While the quasi-transcendental does, in some sense, hinder the possibility of absolute, atemporal conditions of possibilities or explanatory frameworks, its function is not only negative. Rather, the quasi-transcendental points to a certain account of theory or explanatory models as valued not by their ability to predict forthcoming situations, but rather in their ability to clarify such situations on their own terms. What appears, in the end, is that Derrida is a thinker interested in the local, the particular, and its specificities. If deconstruction is, as the opening citation to this text suggested, always adventurous, it is partly because its strength comes out in new, specific contexts which can both be clarified by the logic of repetition-alterity and which suggest new effects associated with it. 


\section{Bibliography}

Caputo, John D. 1987. "Derrida, a Kind of Philosopher: A Discussion of Recent Literature: (Rodolphe Gasché, 'The Tain of the Mirror: Derrida and the Philosophy of Reflection'; Irene E. Harvey, 'Derrida and the Economy of Différance'; John Llewelyn, 'Derrida on the Threshold of Sense')." Research in Phenomenology 17 (January): 245-60.

—. 2000. "Parisian Hermeneutics and Yankee Hermeneutics." In More Radical Hermeneutics. Studies in Continental Thought. Bloomington: Indiana University Press.

- 2006. The Prayers and Tears of Jacques Derrida: Religion without Religion. Bloomington: Indiana University Press.

Derrida, Jacques. 1964. "Violence et Métaphysique: Essai Sur La Pensée d’Emmanuel Levinas (Deuxième Partie)." Revue de Métaphysique et de Morale 69 (4): 425-73.

—. 1972. Marges de La Philosophie. Paris: Editions de Minuit.

- 1982. Margins of Philosophy. Translated by Alan Bass. New York, NY: Harvester Wheatsheaf.

— 1991. L'autre Cap ; Suivi de La Démocratie Ajournée. Paris: Editions de Minuit.

— 1992. The Other Heading: Reflections on Today's Europe. Translated by Pascale-Anne Brault and Michael Naas. Bloomington: Indiana University Press.

_. 1996. Apories. Incises. Paris: Galilée.

—. 1999. "Hospitality, Justice and Responsibility: A Dialogue with Jacques Derrida." In Questioning Ethics: Contemporary Debates in Philosophy, edited by Richard Kearney and Mark Dooley, 65-83. Routledge.

-2000. Foi et Savoir: Suivi de Le Siècle et Le Pardon. Points 447. Paris: Seuil.

- 2001. Writing and Difference. Translated by Alan Bass. London: Routledge Classics.

- 2002. "Faith and Knowledge: The Two Sources of 'Religion' at the Limits of Reason Alone." In Acts of Religion, edited by Gil Anidjar, translated by Samuel Weber, 40-101. New York: Routledge.

Derrida, Jacques, and Anne Dufourmantelle. 1997. De l'Hospitalité. Petite Bibliothèque Des Idées. Paris: Calmann-Lévy.

- 2000. Of Hospitality. Cultural Memory in the Present. Stanford, CA: Stanford University Press. 
Fritsch, Matthias. 2011a. "Deconstructive Aporias: Quasi-Transcendental and Normative." Continental Philosophy Review 44 (4): 439-68.

- 2011b. "Taking Turns: Democracy to Come and Intergenerational Justice." Derrida Today 4 (2): 148-72.

Gasché, Rodolphe. 1986. The Tain of the Mirror: Derrida and the Philosophy of Reflection. Cambridge, Mass: Harvard University Press.

Haddad, Samir. 2013. Derrida and the Inheritance of Democracy. Bloomington: Indiana University Press.

Hägglund, Martin. 2008. Radical Atheism: Derrida and the Time of Life. Stanford, CA: Stanford University Press.

Hoff, Shannon. 2015. "Translating Principle into Practice: On Derrida and the Terms of Feminism." The Journal of Speculative Philosophy 29 (3): 403-14.

Kearney, Richard. 2002. "Strangers and Others: From Deconstruction to Hermeneutics." Critical Horizons 3 (1): 7-36.

Loizidou, Elena. 2007. Judith Butler Ethics, Law, Politics. Abingdon [England]; New York: Routledge-Cavendish.

Rorty, Richard. 1989. “Is Derrida a Transcendental Philosopher?” The Yale Journal of Criticism 2 (2): 207-17.

- 1991. Philosophical Papers, v. 1: Objectivity, Relativism, and Truth.Cambridge; New York: Cambridge University Press.

Wolfreys, Julian. 2003. "Epochalypse [Not] Now." In Glossalalia: An Alphabet of Critical Keywords, edited by Harun Karim Thomas and Julian Wolfreys. Psychology Press. 